\title{
An Analysis of the Warm-Season Diurnal Cycle over the Continental United States and Northern Mexico in General Circulation Models
}

\author{
MYONG-In LeE \\ Goddard Earth Sciences and Technology Center, University of Maryland, Baltimore County, Baltimore, and \\ NASA Goddard Space Flight Center, Greenbelt, Maryland \\ Siegfried D. Schubert And Max J. SuAReZ \\ NASA Goddard Space Flight Center, Greenbelt, Maryland \\ Isaac M. Held, Ngar-Cheung Lau, and Jeffrey J. Ploshay \\ NOAA/Geophysical Fluid Dynamics Laboratory, Princeton, New Jersey \\ Arun Kumar, Hyun-Kyung Kim,* and Jae-Kyung E. Schemm \\ NOAA/NCEP/Climate Prediction Center, Camp Springs, Maryland
}

(Manuscript received 19 September 2005, in final form 28 September 2006)

\begin{abstract}
The diurnal cycle of warm-season rainfall over the continental United States and northern Mexico is analyzed in three global atmospheric general circulation models (AGCMs) from NCEP, GFDL, and the NASA Global Modeling Assimilation Office (GMAO). The results for each model are based on an ensemble of five summer simulations forced with climatological sea surface temperatures.

Although the overall patterns of time-mean (summer) rainfall and low-level winds are reasonably well simulated, all three models exhibit substantial regional deficiencies that appear to be related to problems with the diurnal cycle. Especially prominent are the discrepancies in the diurnal cycle of precipitation over the eastern slopes of the Rocky Mountains and adjacent Great Plains, including the failure to adequately capture the observed nocturnal peak. Moreover, the observed late afternoon-early evening eastward propagation of convection from the mountains into the Great Plains is not adequately simulated, contributing to the deficiencies in the diurnal cycle in the Great Plains. In the southeast United States, the models show a general tendency to rain in the early afternoon-several hours earlier than observed. Over the North American monsoon region in the southwest United States and northern Mexico, the phase of the broadscale diurnal convection appears to be reasonably well simulated, though the coarse resolution of the runs precludes the simulation of key regional phenomena.

All three models employ deep convection schemes that assume fundamentally the same buoyancy closure based on simplified versions of the Arakawa-Schubert scheme. Nevertheless, substantial differences between the models in the diurnal cycle of convection highlight the important differences in their implementations and interactions with the boundary layer scheme. An analysis of local diurnal variations of convective available potential energy (CAPE) shows an overall tendency for an afternoon peak-a feature well simulated by the models. The simulated diurnal cycle of rainfall is in phase with the local CAPE variation over the southeast United States and the Rocky Mountains where the local surface boundary forcing is important in regulating the diurnal cycle of convection. On the other hand, the simulated diurnal cycle of rainfall tends to be too strongly tied to CAPE over the Great Plains, where the observed precipitation and CAPE are out of phase, implying that free atmospheric large-scale forcing plays a more important role than surface heat fluxes in initiating or inhibiting convection.
\end{abstract}

* Current affiliation: Korea Meteorological Administration, Seoul, South Korea.

Corresponding author address: Dr. Myong-In Lee, Global Modeling and Assimilation Office, Code 610.1, NASA Goddard Space Flight Center, Greenbelt, MD 20771.

E-mail: milee@gmao.gsfc.nasa.gov

DOI: $10.1175 / J H M 581.1$

(C) 2007 American Meteorological Society 


\section{Introduction}

The diurnal cycle is a fundamental component of the warm-season climate of the continental United States and northern Mexico. For example, the Great Plains low-level jet (GPLLJ) transports almost one-third of all the moisture that enters the continental United States with most of the influx from the GPLLJ (slightly less than two-thirds of it) entering during the 12 nighttime hours (Helfand and Schubert 1995; Higgins et al. 1997). Similarly, in the southwestern United States and northwestern Mexico, model simulations and observations show that the Gulf of California low-level jet (GCLLJ), land-sea breezes, and heating/cooling over the elevated Sierra Madre Occidental (SMO), all contribute to a complex diurnal evolution that serves to define the warm-season climate in that region (e.g., Berbery 2001; Anderson et al. 2001).

The diurnal cycle is impacted by and affects variability on a wide range of time scales. Arritt and Mitchell (1994) examined the interaction between the GPLLJ and mesoscale convection, and Schubert et al. (1998) show that the GPLLJ is also modulated on synoptic and longer time scales. Wilson and Mitchell (1986) and Lin et al. (2000) show strong linkages between the mean climate and the diurnal cycle. Evidence for a strong link between the diurnal cycle and the monsoon is demonstrated by Randall et al. $(1985,1991)$, who showed that the diurnal cycle impacts the partitioning of precipitation between the land and ocean, and leads to a cooler land surface and a decrease of precipitation in summer monsoon regions.

While the atmospheric diurnal cycle is ultimately driven by the regular daily variation in solar radiation, it is a complex phenomenon that exhibits large geographical differences in timing, amplitude, and in the underlying physical mechanisms. Precipitation, for example, has a nocturnal maximum over the Great Plains (GP), while it has a late afternoon maximum over the southeastern United States, over the Rockies, and over the western slopes of the SMO (Wallace 1975; Easterling and Robinson 1985; Dai et al. 1999; Berbery 2001). These geographical differences are also evident in the recent high-resolution geostationary satellite observations (Tian et al. 2005). To complicate matters further, the diurnal cycle in precipitation also demonstrates considerable dependence on intensity. Over the GP, rainfall maxima for the heaviest rainfall occur in the late afternoon, and the maximum shifts progressively later at night as the rainfall intensity is reduced (Wallace 1975; Riley et al. 1987).

A number of mechanisms are believed to be important in producing the geographic differences in the di- urnal cycle of precipitation. Over the GP region, Riley et al. (1987) discuss the role of mountain-generated storm systems, including mesoscale convective systems (MCSs) [or mesoscale convective complexes (MCCs); Maddox et al. 1980], that tend to move eastward from the Rocky Mountains onto the Plains after sunset, and produce some (but not all) of the diurnal variability in the GP. Because of their relatively longer lifetime, the rainfall peaks of the MCSs usually occur in the late evening through midnight over the GP region, while non-MCS rainfall peaks in the late afternoon (McAnelly and Cotton 1989; Nesbitt and Zipser 2003). Carbone et al. (2002) suggested that gravity waves may contribute to the propagation speed of major convective episodes over this region. Other studies highlight the subcontinental and large-scale regulation of diurnal convection as well as the importance of the GPLLJ (e.g., Rasmusson 1967; Helfand and Schubert 1995; Higgins et al. 1997) in contributing to nighttime boundary layer convergence that favors nocturnal convection in that region.

Over the SMO, monsoonal precipitation is associated with sea breezes that lead to enhanced moisture flux and convergence followed by heavy afternoon precipitation, while a reversed circulation with precipitation along and off the coast develops during the early morning (Berbery 2001; Tian et al. 2005). In the Gulf of California, the GCLLJ contributes to the flux of moisture into the southwest, though the spatial scale of the jet is smaller than in the GP, and the relative contribution of the jet to the diurnal cycle is less well known, in large part due to the lack of adequate observations (Higgins et al. 2006). Large-scale thermally driven atmospheric tides also contribute to diurnal variations (Dai and Deser 1999; Dai et al. 1999; Lim and Suh 2000). Other factors impacting the diurnal cycle include interactions with clouds (Wilson and Mitchell 1986; Randall et al. 1991; Bergman 1997; Soden 2000), interactions with the land surface (Betts and Ball 1995; Chang et al. 2000; Schulz et al. 2001), landscape changes (Markowski and Stensrud 1998), and radiative heating over deserts (Douglas and Li 1996).

It is not surprising from the above discussion that the simulation of the diurnal cycle of precipitation is a difficult test for atmospheric general circulation models (AGCMs). A number of studies have examined the diurnal cycle produced in regional and global AGCMs (e.g., Slingo et al. 1987; Randall et al. 1991; Garratt et al. 1993; Betts et al. 1996; Chen et al. 1996; Giorgi and Shields 1999; Dai et al. 1999; Lin et al. 2000; Groisman et al. 2000; Yang and Slingo 2001; Trenberth et al. 2003; Zhang 2003; Tian et al. 2004). These studies show a number of problems in the United States and northern 


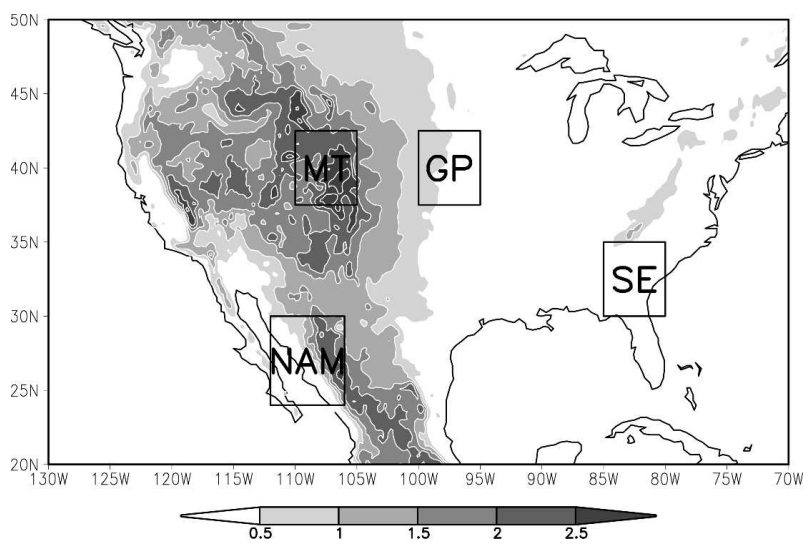

FIG. 1. Surface elevation (km) over the analyzed domain. Four grid boxes are indicated in the map to represent the diurnal cycle over the Southeast (SE; $30^{\circ}-35^{\circ} \mathrm{N}, 80^{\circ}-85^{\circ} \mathrm{W}$ ), Great Plains (GP; $37.5^{\circ}-42.5^{\circ} \mathrm{N}, 95^{\circ}-100^{\circ} \mathrm{W}$ ), Rocky Mountains (MT; $37.5^{\circ}-42.5^{\circ} \mathrm{N}$, $105^{\circ}-110^{\circ} \mathrm{W}$ ), and the North American monsoon (NAM; $25^{\circ}-$ $30^{\circ} \mathrm{N}, 105^{\circ}-110^{\circ} \mathrm{W}$ ) regions.

Mexico that appear to be common to many AGCMs. These include difficulties in simulating the nocturnal precipitation over the GP; a phase bias in the diurnal cycle of precipitation amount that is too early over the southern and eastern United States; excessive afternoon precipitation over the western slopes of the SMO; and overestimated frequency and underestimated intensity of the precipitation diurnal cycle, probably due to too-frequent convections in low intensities (Chen et al. 1996; Dai et al. 1999). While regional (high-resolution nested) models tend to fare somewhat better than the coarser uniform-resolution global models in simulating the diurnal cycle, they are far from perfect and exhibit many of the same problems (Leung et al. 2003). Many of these problems appear to be linked to the models' convective parameterizations, and how the schemes interact with the land surface, the boundary layer, and clouds. Other problems appear to be related to inadequate resolution, and incorrect regional and larger-scale interactions that act to modulate the local convective processes.

The current study is a coordinated effort to evaluate and understand the warm-season diurnal cycle in current AGCMs. The focus is on the continental United States and northern Mexico. The domain (Fig. 1) contains geographically diverse subregions, and is large enough to investigate the local-, regional-, and continental-scale influences on the diurnal cycle simulation. In addition, a number of validation datasets are available for this region, including long-term hourly station records of precipitation and a high-resolution regional reanalysis. The forthcoming observations from the North American Monsoon Experiment (NAME) field campaign (Higgins et al. 2006) are anticipated to be useful for future model validation efforts.

Three different AGCMs from the National Centers for Environmental Prediction (NCEP), the Geophysical Fluid Dynamics Laboratory (GFDL), and the National Aeronautics and Space Administration Global Modeling and Assimilation Office (NASA GMAO) are investigated in this study. The AGCMs are evaluated at a typical climate model resolution (approximately $2^{\circ}$ latitude-longitude), in order to address 1) how accurately current climate models resolve the observed characteristics of warm-season diurnal cycle of rainfall, 2) how faithfully they simulate the local and large-scale forcing mechanisms that drive the diurnal convection, and 3) possible improvements and limitations in the current physical parameterizations. The hypothesis is that a careful assessment of several models (run and evaluated in a controlled environment) can more readily distinguish between fundamental problems and tuning issues that affect the representation of the diurnal cycle. Furthermore, the results should provide guidance on the improvements that are possible with modifications to existing schemes, versus those that will require fundamental advances to our models. A followon study addresses the issue of the improvements that are possible with higher resolution (Lee et al. 2007).

Section 2 describes the models, experiments, validation methods, and datasets. Section 3 describes the observed and simulated characteristics of the diurnal cycle of rainfall and low-level winds. The local and largescale forcing mechanisms that drive diurnal convection are examined in section 4. Section 5 discusses the results of experiments that examine the sensitivity of selected parameters in the cumulus convection scheme on the simulated diurnal cycle of rainfall. Section 6 summarizes the major findings and provides further discussion.

\section{Models and experiments}

\section{a. Models}

Table 1 describes the relevant characteristics of the three AGCMs examined in this study. The GFDL model [Global Atmosphere Model (AM2)] has a gridpoint dynamical core, with 24 vertical levels in a hybrid coordinate. Moist convection is represented by the relaxed Arakawa-Schubert (RAS) formulation of Moorthi and Suarez (1992). The cloud scheme consists of a prognostic microphysics parameterization for cloud liquid water and ice (Rotstayn 1997) and a prognostic cloud fraction parameterization (Tiedtke 1993). The boundary layer scheme is a modified version of the Lock et al. (2000) scheme, while the land model has 
TABLE 1. Description of the models.

\begin{tabular}{llcl}
\hline \hline \multicolumn{1}{c}{ Group } & Model & Resolution $($ lat $\times$ lon, vertical layers) & \multicolumn{1}{c}{ Convection } \\
\hline GFDL & AM2 & $2^{\circ} \times 2.5^{\circ}$, L24 & Relaxed Arakawa-Schubert (Moorthi and Suarez 1992) \\
NCEP & GFS v2 & T62 $\left(\sim 2^{\circ} \times 2^{\circ}\right)$, L64 & Simplified Arakawa-Schubert (Grell 1993; Pan and Wu 1995) \\
NASA/GMAO & NSIPP-2 & $2^{\circ} \times 2.5^{\circ}$, L40 & Relaxed Arakawa-Schubert (Moorthi and Suarez 1992) \\
\hline
\end{tabular}

multiple subsurface layers with a bucket hydrology, and river routing scheme. Other details of the model physics are described in Anderson et al. (2004).

The NCEP model [Global Forecasting System (GFS) version 2] is a spectral model with 64 sigma levels in the vertical. The deep convection is parameterized based on a simplified version of the Arakawa-Schubert scheme (Arakawa and Schubert 1974) by Grell (1993) and Pan and $\mathrm{Wu}$ (1995). Cloud fraction is computed diagnostically ( $\mathrm{Xu}$ and Randall 1996) as a function of prognostic cloud liquid water with a condensation process based upon a saturation of relative humidity criteria (Sundqvist et al. 1989; Zhao and Carr 1997). The model includes the boundary layer scheme of Hong and Pan (1996), and the land surface model based on Pan and Mahrt (1987).

The NASA GMAO model used in this study is version 2 of NASA's Seasonal to Interannual Prediction Project (NSIPP) model. It is a gridpoint model with 40 sigma levels in the vertical. Deep convection is parameterized using RAS, the same scheme used in the GFDL model. The grid-scale condensation and cloud generation is parameterized using a relative humidity scheme and includes a prognostic cloud liquid water scheme. The boundary layer is parameterized using the simple diffusivity scheme of Louis et al. (1982). The land surface model is the mosaic scheme of Koster and Suarez (1996). A detailed description of the model can be found in Bacmeister et al. (2000).

Each AGCM was run at its "standard" climate resolution. In the horizontal, all three models have about the same resolution (200-250-km grid spacing), but in the vertical the resolution differs considerably, ranging from 24 levels in the GFDL model to 64 levels in the NCEP model.

In anticipation of the sensitivity of the results to the parameterization of convection, we next look at the differences in the deep convection schemes in the three AGCMs in more detail.

\section{b. Deep convection parameterizations}

The original Arakawa-Schubert convection scheme relies on the quasi-equilibrium assumption, in which the rate of stabilization by cumulus mass flux equals the rate of destabilization by large-scale processes. It also assumes a spectrum of cumulus clouds within a grid box, which are characterized by different entrainment rates and detraining levels. The cloud work function (CWF) is the CAPE for an entraining plume. It is computed for each cloud by integrating parcel buoyancy from the cloud base to the nonbuoyant cloud top where only the positive CWF contributes to the total cumulus mass flux.

The GFDL and NASA models both use RAS. This convection scheme relaxes the CWF for each cloud back to a critical value over a fixed time scale (Moorthi and Suarez 1992) rather than making instantaneous adjustments to the equilibrium state as in the original Arakawa-Schubert scheme. The critical value of the CWF is specified and is not state dependent but increases with increasing cloud-top height. The relaxation time scale is a free parameter to be determined in each model. The NASA model uses a fixed relaxation time scale of $30 \mathrm{~min}$ for all convective plumes with a 5-min model time step. On the other hand, the time scale for the GFDL model varies from $2 \mathrm{~h}$ for the shallowest plume to $12 \mathrm{~h}$ for the deepest plume with a $30-\mathrm{min}$ model time step. The cloud base is defined as the lifting condensation level (LCL) in the GFDL model, while it is specified as the second lowest level in the NASA model.

Neither model has downdrafts; however, both models include the evaporation of convective rainfall. They also include a simple diffusive vertical convective momentum transport scheme, with a diffusivity that is proportional to the total mass flux multiplied by the depth of the convection. Both models also adopt the minimum entrainment constraint for the spectrum of entraining plumes (Tokioka et al. 1988) as an additional convection inhibition/trigger function.

The deep convection scheme in the NCEP model, the simplified Arakawa-Schubert scheme (SAS), is slightly different from that in the two other models. A major difference is that it treats only the deepest single plume, rather than considering multiple plumes as in the original Arakawa-Schubert scheme or the RAS scheme. The CWF relaxes with a time scale of 20-60 min depending on the vertical velocity at the cloud base, using a model time step of $15 \mathrm{~min}$. The critical CWF is also a function of the cloud-base vertical motion so that it is 
allowed to approach zero as the large-scale rising motion becomes strong. The cloud base is defined as the level of free convection (LFC).

The NCEP cloud model incorporates a downdraft mechanism as well as the evaporation of precipitation. Mass fluxes induced in the updraft and the downdraft are allowed to transport momentum. Reevaporation of precipitation is scaled following the Kessler-type microphysics. For an additional trigger function, the model uses a criterion that the level of free convection must exist and must be within $150 \mathrm{hPa}$ of the parcel starting level. Unlike the other two models, the NCEP model employs a diffusion-type nonprecipitating shallow convection scheme (Tiedtke 1983) that supplements the deep convection scheme.

Among the many free parameters in the cumulus scheme, the convective cloud base and the cumulus relaxation time scale are particularly influential in controlling the phase of the simulated diurnal convection, and this will be the focus of the latter part of this study (section 5).

\section{c. Experiments and analysis}

To avoid potential statistical sampling problems associated with interannual variability, we simplify matters by forcing the models with observed climatologicalmean sea surface temperatures (SSTs). The same climatological SST and sea ice forcing was prescribed in all three AGCMs. The SST and sea ice climatology is a 20-yr (1983-2002) average of the Reynolds et al. (2002) optimum interpolation (OI) monthly SST data. The models were integrated for five months from 1 May initial conditions. The diurnal cycle was computed from the three months of summer (June-August), allowing for a one-month spinup from the 1 May initial conditions (September was not used in the analysis). To increase the reliability of the statistics of the diurnal cycle, especially for rainfall, five ensemble members were generated with each model. Each ensemble member was started from different atmospheric and land surface initial states: these states were chosen arbitrarily for each model from preexisting May model restarts. These restarts were taken from different years of preexisting long simulations forced with observed SSTs. Previous studies have shown that warm-season rainfall depends on the preceding soil moisture conditions, particularly over the GP (Koster et al. 2004), which is in turn influenced by the interannual variation of SST forcing. We would therefore expect that the diurnal cycle of rainfall is impacted by soil moisture as well (e.g., Hu 2003). In fact, an inspection of the individual ensemble members shows that the amplitude of the simulated diurnal cycle of rainfall does indeed vary considerably among the ensemble members, though that is not the case for the phase of the diurnal cycle (our main focus).

To validate the hourly simulated precipitation rates, we compare the results to the observed hourly precipitation dataset (HPD) developed by Higgins et al. (1996). This dataset was created at NCEP/Climate Prediction Center (CPC) from quality-controlled station records (about 2900 rain gauge sites) and gridded to $2^{\circ}$ latitude by $2.5^{\circ}$ longitude grids over the United States. Three-hourly zonal $(u)$ and meridional $(v)$ winds, temperature, humidity, and surface pressure fields from the NCEP North American Regional Reanalysis (NARR; Mesinger et al. 2006) were used to calculate the diurnal cycles of CAPE, the low-level jet, and moisture flux. We note that, although the above fields come from assimilation, the diurnal variations in those fields over the GP are quite realistic when compared with the Atmospheric Radiation Measurement (ARM) sounding datasets. The NARR also provides 3-hourly estimates of precipitation. The NARR rainfall assimilation makes use of daily analyses of surface rain gauge observations, and disaggregates them into hourly values using temporal weights derived from the HPD over the continental United States. It is therefore not surprising that the diurnal cycles of the rainfall from the two datasets are very similar. In fact, we find that the differences between the NARR and HPD mean rainfall amount are smaller than $0.5 \mathrm{~mm}$ day $^{-1}$ over the most of the continental United States. In the following, we use the hourly sampled HPD dataset to derive accurate amplitude and phase of the rainfall diurnal cycle over the U.S. region, whereas we use the 3-hourly NARR rainfall over the rest of domain not covered by the HPD dataset. We limit our study to the land areas, since that is where the observations are most reliable.

The seasonal mean (June-August) diurnal cycle of precipitation amount was calculated following Dai et al. (1999) by adding up all precipitation for a given hour of the day and dividing it by total number of days (92 days in this case). The amplitude and phase of the maximum were determined from the diurnal time series. We also normalized the amplitude (equal to the maximum minus the 24-h mean) by the 24-h mean and present the normalized amplitude as a percentage. Normalized amplitudes and the phases were then averaged over $20 \mathrm{yr}$ to obtain the observed climatological mean diurnal cycle. For the simulations, the results were averaged over the five ensemble members.

In section 4, we analyze the local convective instability as measured by

$$
\mathrm{CAPE}=\int_{p t}^{p b} R_{d}\left(T_{\mathrm{vp}}-T_{\mathrm{ve}}\right) d \ln p,
$$


(a) NARR
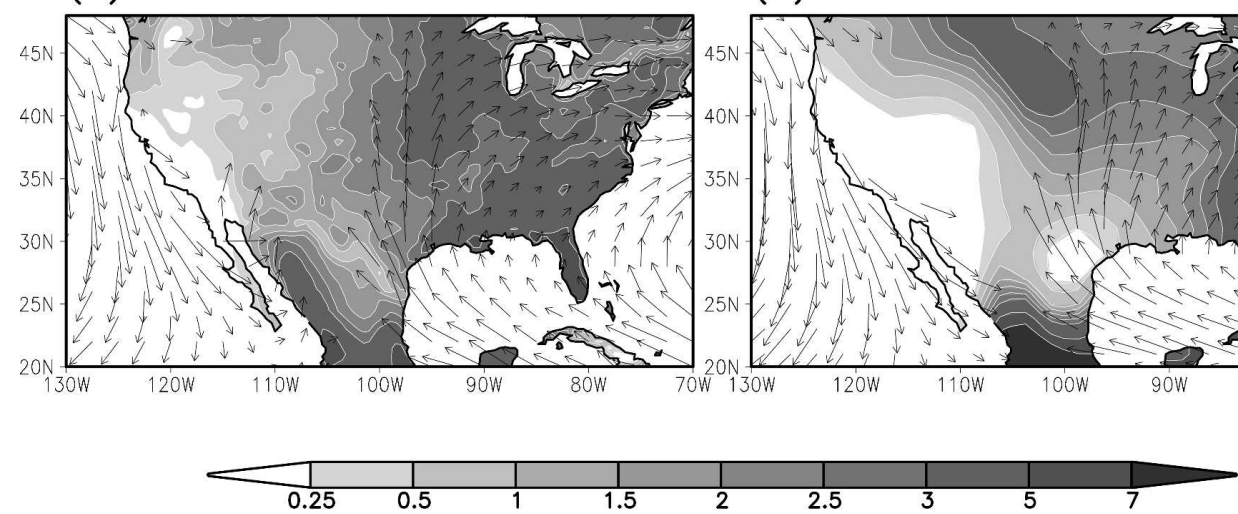

(c) NCEP

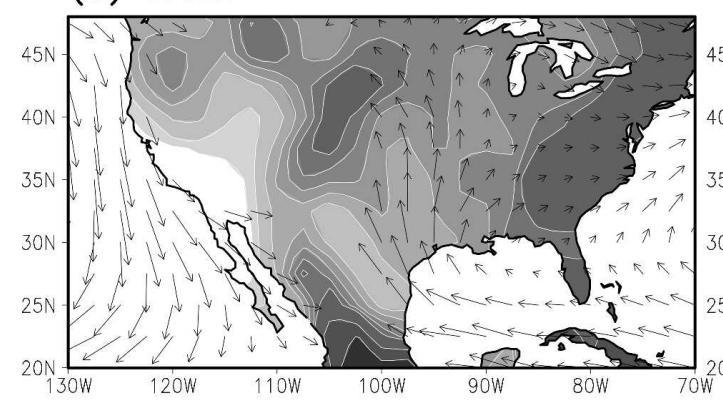

(b) GFDL

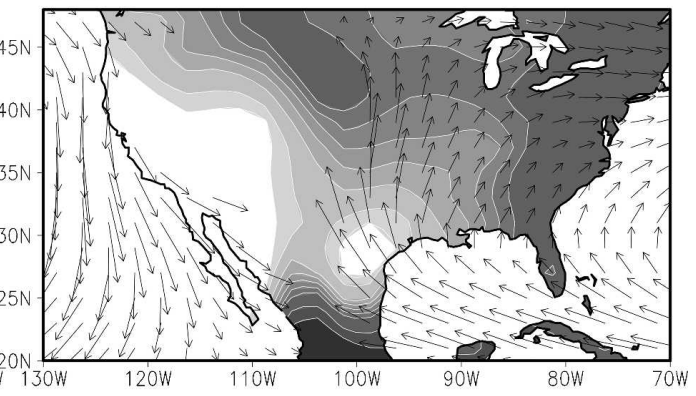

(d) NASA

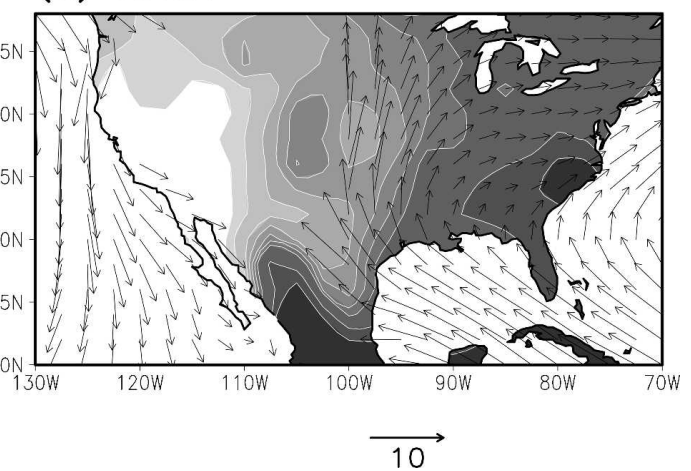

FIG. 2. June-August (JJA) mean precipitation rate $\left(\mathrm{mm} \mathrm{day}^{-1}\right)$ and $925-\mathrm{hPa}$ wind $\left(\mathrm{m} \mathrm{s}^{-1}\right)$ from (a) NARR and three models from (b) GFDL, (c) NCEP, and (d) NASA. The model results are the averages of five ensemble members run with climatological SST. The NARR results are a long-term climatology (1983-2002). Wind vectors are masked out below the ground level.

where $R_{d}$ is the gas constant, and $T_{\mathrm{vp}}$ and $T_{\mathrm{ve}}$ are the virtual temperatures of the parcel and environment, respectively. Here $p_{t}$ is the cloud-top pressure where the buoyancy vanishes and $p_{b}$ is pressure from which the parcel is lifted. The CAPE is interpreted as the maximum available energy that can be transferred to deep convective motion. As defined in this study, it can be considered the sum of negative buoyancy from $p_{b}$ to $p_{\mathrm{LFC}}$ and positive buoyancy from $p_{\mathrm{LFC}}$ and $p_{t}$. The negative buoyancy or convective inhibition (CIN) is usually interpreted as the amount of energy needed to initiate convection (the convective barrier). We note that CAPE is not the same as the CWF that the deep convection schemes actually rely on for estimating parcel buoyancy. The CWF includes the entrainment mixing of the convective plumes when lifted, which effectively lowers the cloud top $\left(p_{t}\right)$. In practice, the CWF is a complicated function of height (for multiple plumes), the relaxation time scale, and various trigger/inhibition functions, which are implemented in different ways among the models. Since the CAPE does not depend on the details of the convection schemes, it is a useful general diagnostic for comparing the local convective instability in the models.

\section{Warm-season diurnal cycle}

\section{a. Diurnal cycle of rainfall}

Before evaluating the diurnal cycle of precipitation, the summer-mean (June-August) precipitation rates and 925-hPa winds in the NARR and three model simulations are compared at first in Fig. 2. Overall, the rainfall simulations compare reasonably well with the reanalysis, with wet conditions in the southeastern United States and dry conditions in the western part of the country. The models also simulate reasonably well the meridionally elongated North American monsoon front over the western slope of the SMO in northwestern Mexico, as part of the northward extension of the summertime intertropical convergence zone (ITCZ). Some common biases are, however, evident in the simulated mean rainfall patterns. The models are in 
(a) HPD
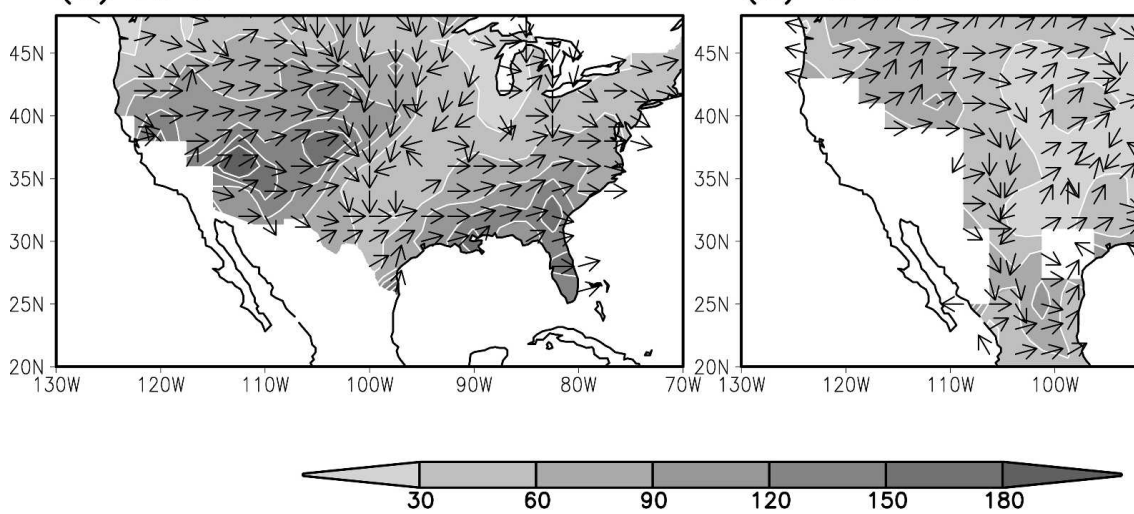

(c) NCEP

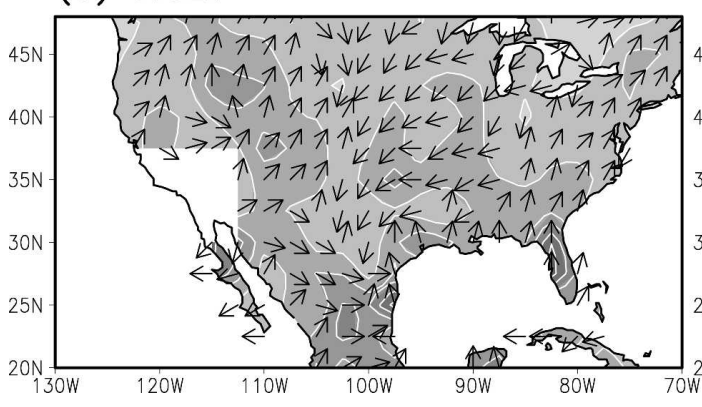

(d) NASA

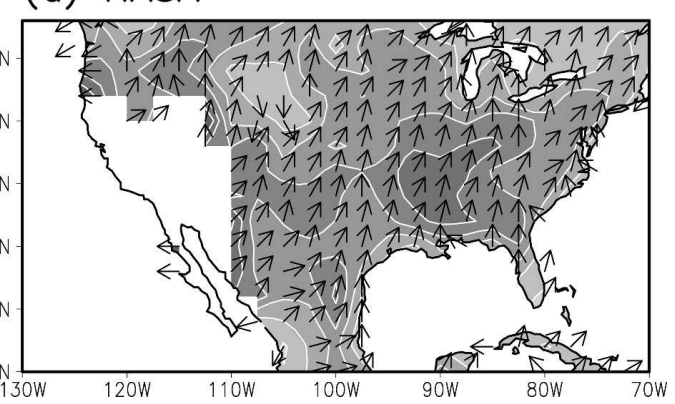

FIG. 3. Diurnal cycle of JJA mean precipitation amount. Normalized amplitude of the diurnal cycle is indicated as a percent (shaded), and the phase of the maximum is indicated by the local solar time (arrow pointing south $=$ 0000 LST, west $=0600 \mathrm{LST}$, north $=1200 \mathrm{LST}$, and east $=1800 \mathrm{LST})$. (a) From NCEP HPD covering the continental United States and averaged for the period 1983-2002. The (b) GFDL, (c) NCEP, and (d) NASA models. Ocean points and very dry land areas $\left(<0.1 \mathrm{~mm} \mathrm{day}^{-1}\right.$ of daily total precipitation) are masked out.

general too dry over the western United States and the western part of the Rocky Mountains. In addition, the simulated North American monsoon rainbands tend to retreat southward, contributing to a drier Arizona-New Mexico. All three models have wet biases over the southern part of Mexico.

Rainfall biases are also evident in the midcontinent, particularly over the GP region. For example, the models are all too dry in the central plains $\left(35^{\circ}-45^{\circ} \mathrm{N}, 100\right.$ $\left.90^{\circ} \mathrm{W}\right)$. The tendency for the models to shift the local maxima to the west or northwest over the elevated terrain appears to be a common bias in AGCMs.

The simulated low-level winds reproduce the two oceanic anticyclones, one in the North Atlantic and the other in the North Pacific. The strong southerlies associated with the GPLLJ are also reasonably well simulated in all three models. However, the three models do not simulate the southerly component of the low-level winds in the Gulf of California and the southwestern United States, implying that the horizontal resolution of current simulations is insufficient to resolve the re- gional details of the North American monsoon circulation (Lee et al. 2007).

Figure 3 shows the diurnal cycle of rainfall in terms of normalized amplitude and time of maximum. The observations show large amplitudes in the diurnal cycle located over the southeastern United States and the Rocky Mountains, where the maximum exceeds the 24-h daily mean by nearly a factor of 2 or 3. The amplitude in the diurnal cycle of the simulated rainfall varies considerably among the models, with relatively weaker amplitudes in the GFDL and NCEP models, and stronger amplitudes in the NASA model in most of the region. The geographical distribution of the amplitude also varies among the models. The NASA model shows larger amplitudes in the south-central United States, while the distribution in the GFDL and NCEP models is similar to the observed, with maxima in the southeastern United States and west of the Rocky Mountains.

Regarding the phase of the diurnal cycle, most regions over the United States are characterized by late 

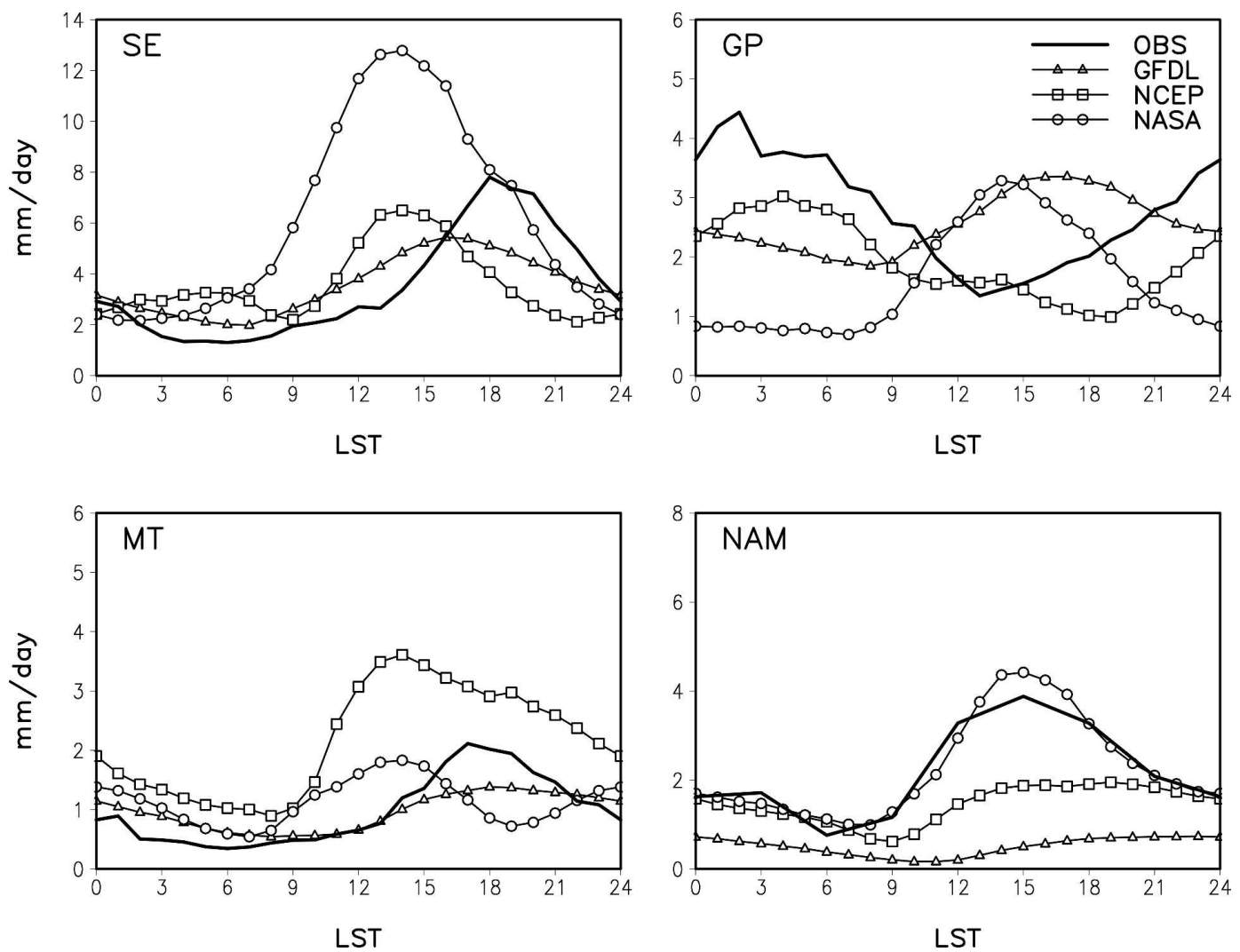

FIG. 4. Averaged diurnal variation of precipitation rate $\left(\mathrm{mm} \mathrm{day}^{-1}\right)$ over the four regions defined in Fig. 1 . The JJA mean variations from the observations (solid thick line), GFDL (triangle), NCEP (square), and NASA (circle) are indicated in LST. The observations are from the NCEP HPD except for the NAM region where the 3-hourly NARR is used instead.

afternoon or evening peaks [around 1800 local solar time (LST)], except for the nighttime peaks that occur over the eastern slopes of the Rocky Mountains and adjacent GP (Dai et al. 1999). Over the Rocky Mountains and adjacent GP, the time of the maximum translates systematically toward the east from late afternoon (along $105^{\circ} \mathrm{W}$ ) to midnight (along $100^{\circ} \mathrm{W}$ ), and 0300 $0400 \mathrm{LST}$. (along $90^{\circ} \mathrm{W}$ ): this is seen clearly in a recent high-resolution satellite-derived rainfall analysis (Tian et al. 2005). The models show wide variations in phase of the maximum. The GFDL model shows relatively good agreement with observations over the northwestern part of Rocky Mountains and over the southeastern United States, with an early bias of less than 1-2 h. An organized area of nocturnal rain (peaking around midnight) was also simulated over the states of Colorado and New Mexico (along the $105^{\circ} \mathrm{E}$ ), which is, however, shifted west of the elevated terrain compared with observations. The NCEP model shows a clear variation over the continent in the phase of the diurnal rainfall peak. The model simulates nighttime maxima over a wide area of the central United States, including the
GP. In other regions, daytime peaks occur a few hours too early in the afternoon. In contrast with the other two AGCMs, the NASA model shows a relatively uniform signal in the phase of the maximum rain, with early afternoon precipitation (1300-1500 LST) over much of the region.

The diurnal variations of rainfall amount for the selected regions of geographically different characteristics are compared in Fig. 4, where the four regions are chosen as indicated in Fig. 1: the southeastern United States (SE), the Great Plains (GP), the Rocky Mountains (MT), and the North American monsoon region (NAM). The time series of rainfall amount consists primarily of a wavenumber- 1 harmonic in the models as well as in the observations. Small secondary maxima are simulated in the NCEP model in the SE, and in the NASA model in the MT. The amplitude and phase of the observed diurnal cycle shows the largest amplitudes over the SE, whereas the smallest occur over the MT. The NASA model tends to overestimate the amplitude, particularly over the rainy areas of SE and NAM, while the GFDL and NCEP models underestimate the ob- 


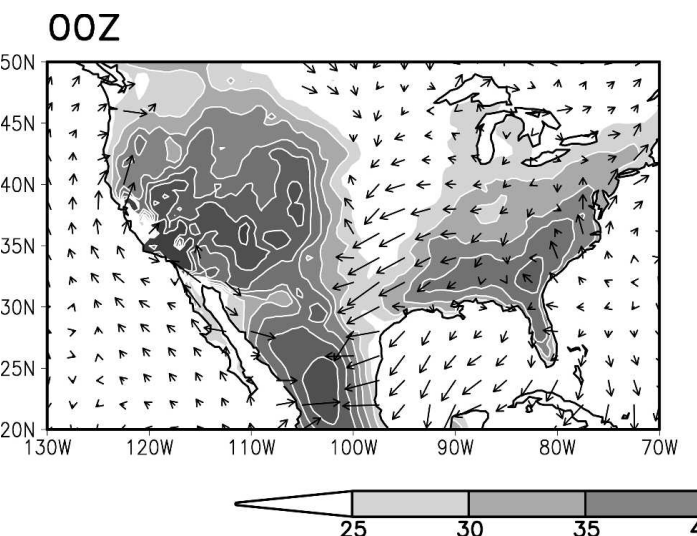

$12 Z$

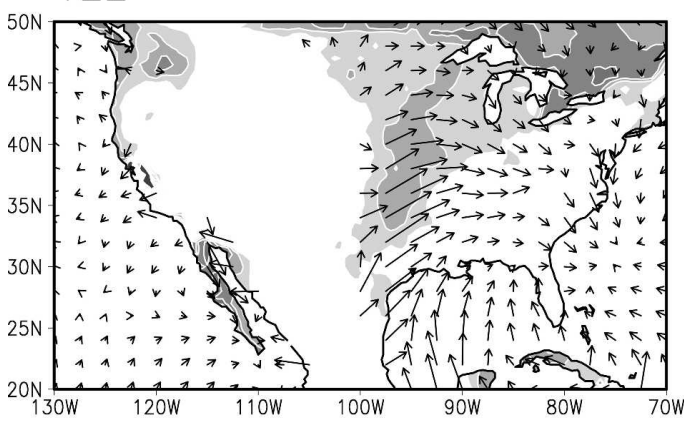

$06 Z$

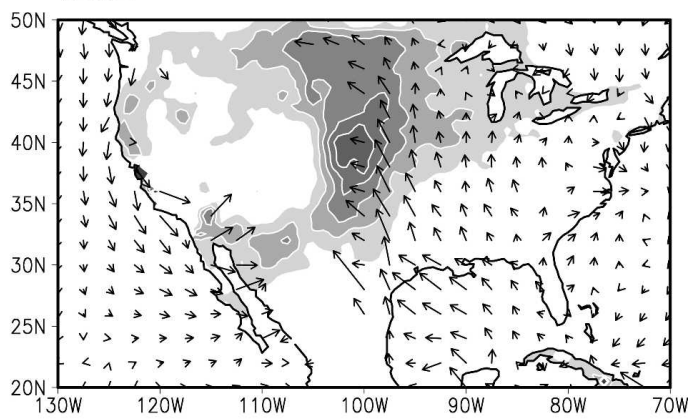

$18 Z$

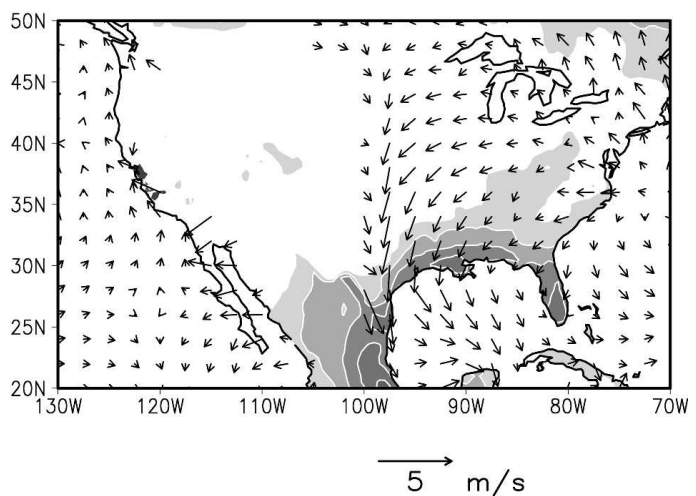

FIG. 5. The diurnal component of observed precipitation and low-level wind from NARR. The precipitation is the accumulated rainfall amount for the previous $6 \mathrm{~h}$ presented as a percent of the daily total rainfall. Winds are diurnal departures from the daily mean at 0000, 0600, 1200, and 1800 UTC.

served amplitude. Phase biases are such that there is some tendency for rainfall to occur $1-3 \mathrm{~h}$ early over the SE and the MT in the NCEP and NASA models. The GFDL model shows late afternoon or evening peaks in most regions (generally later than the other two models), with a wider distribution of rainfall in time. Only the NCEP model shows nighttime amplification and daytime suppression of rainfall in the GP region as observed, although it lags the observed peak by a few hours.

A decomposition of the total rainfall into convective and nonconvective grid-scale condensation shows that the deep convection schemes in the models account for more than $70 \%-80 \%$ of the total rainfall in this region, implying that the deep convection scheme is primarily responsible for the misrepresentation of the diurnal cycle.

\section{b. Spatial and temporal structures}

Figure 5 shows the evolution of the diurnal component of rainfall and low-level winds at 0000, 0600, 1200, and 1800 UTC, from the NARR data averaged over 20 yr (1983-2002). The diurnal cycle of precipitation de- velops in southern Mexico and the southern United States surrounding the Gulf of Mexico around 1800 UTC (early afternoon in SE). In the next $6 \mathrm{~h}(0000$ UTC), most regions of the continent exhibit a maximum of rainfall, except over the Midwest and GP. During that period, three regions with afternoon maxima are identified, consisting of the southeastern United States, the southwestern United States, and the western slope of SMO. By 0600 UTC (around local midnight in $\mathrm{SE}$ ), precipitation in those regions is much suppressed, and the eastern slopes of the Rocky Mountains and northwestern Mexico become active. By 1200 UTC (local morning in GP), the precipitation center is located over the GP. In the southeastern United States, the center of precipitation has a tendency to expand northward and eastward during the afternoon, while the mountain-initiated precipitation over the Rocky Mountains tends to propagate away to the surrounding regions in the local evening and nighttime. One of the precipitation centers moves eastward to the GP where it is closely associated with an intensification of the GPLLJ (0600 and 1200 UTC). By transporting mois- 
GFDL

NCEP

NASA
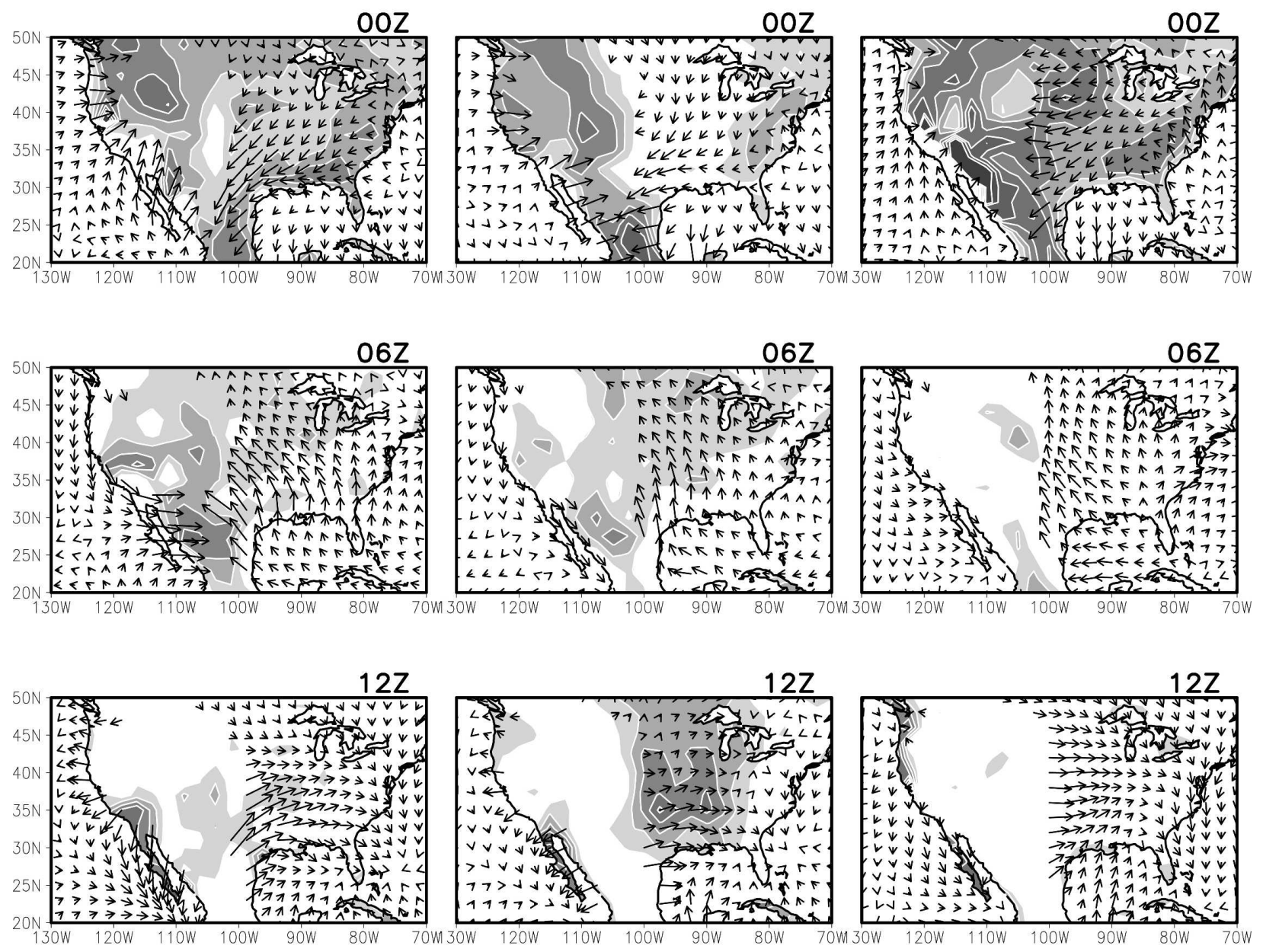

$18 Z$
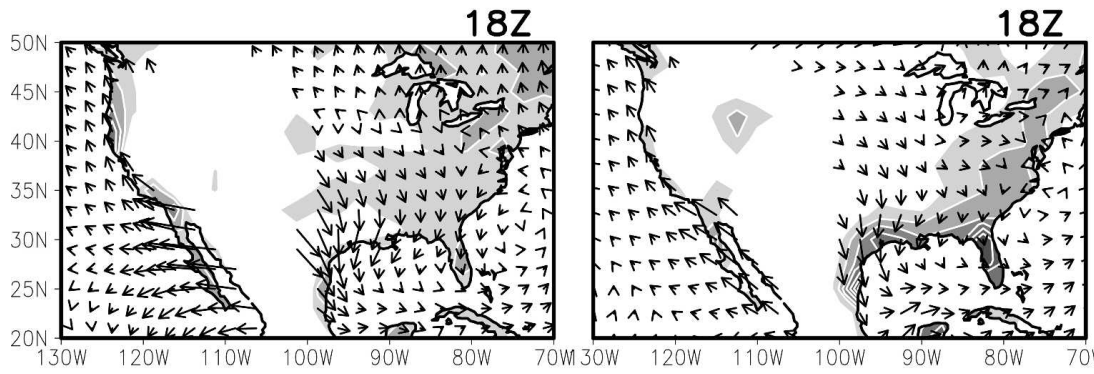

$18 Z$

$18 Z$

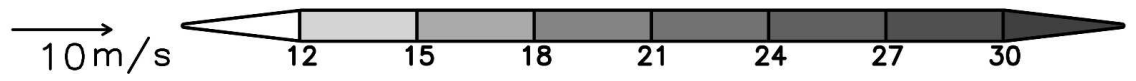

FIG. 6. The diurnal variations of the simulated precipitation and 925-hPa wind from the (left) GFDL model, (center) NCEP model, and (right) NASA model.

ture from the Gulf of Mexico, the jet provides favorable large-scale forcing to produce nocturnal precipitation over the Midwest and GP region. During the morning, the precipitation over the midcontinent is suppressed as the anomalous wind changes from southerlies to northerlies as the GPLLJ decays.

The simulated diurnal variations of rainfall and lowlevel winds are compared in Fig. 6. The GFDL model 

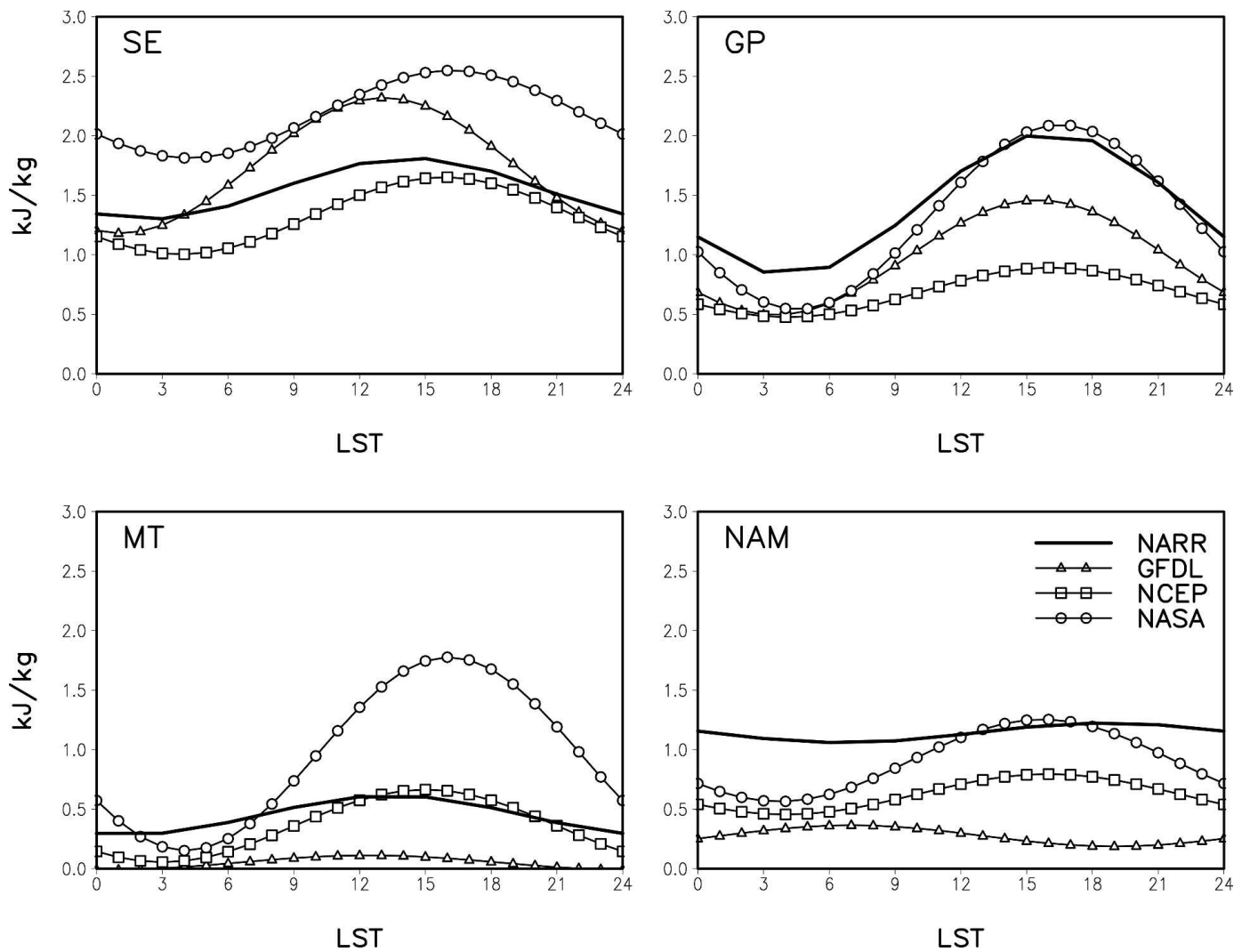

FIG. 7. Same as in Fig. 4, but for the CAPE. The CAPE at each grid point was filtered using a Fourier filter, retaining the time mean and the $24-\mathrm{h}$ harmonic, and then area averaged over the four grid boxes.

shows a relatively good simulation of rainfall over the southeastern United States where the convective activity develops at 1800 UTC, and reaches its maximum at 0000 UTC. The model also produces weak nocturnal rainfall over the midcontinent at 0600 and 1200 UTC, although the convection centers are not as organized as in the reanalysis. The simulated convection over the Rocky Mountains reaches maximum values later than in the reanalysis. The model also tends to spread rainfall too widely in time in most locations, consistent with the time series shown in Fig. 4. The NCEP model shows quite realistic patterns of diurnal rainfall variation. For example, the model correctly captures the daytime precipitation signals in the southern United States (1800 UTC), and in the eastern and western United States (0000 UTC). It also captures the nocturnal rainfall over the central United States after local midnight (06001200 UTC), although the model shows a significant delay in the precipitation maximum at 1200 UTC. The NASA model has very little geographical variation in the diurnal cycle of precipitation, with maximum rainfall occurring during 1800-0000 UTC in most regions.

The diurnal variations of low-level wind in the three models are in relatively good agreement with the re- analysis in terms of wind directions, although all three models have amplitude biases (note the different wind scales in Fig. 6). The models show a realistically large diurnal variation in the central United States associated with the nocturnal GPLLJ. They correctly simulate the southerly wind departures over the central United States during the nighttime (at 0600 and 1200 UTC) and the northerly departures during the daytime (at 0000 and 1800 UTC). In general, the models show less covariability between the low-level wind and rainfall over the central United States, although there are substantial differences between the models (relatively strong in the NCEP model, and weaker in the NASA model).

\section{Influence of local versus large-scale forcing}

\section{a. Diurnal variation of $C A P E$}

To gain some insight into the underlying mechanism of diurnal rainfall variation, the diurnal variation of CAPE was analyzed in the NARR and the three models. Figure 7 shows the variation of CAPE in our four grid boxes of interest (Fig. 1). Only one summer (JuneAugust 1995) was analyzed from NARR, while for the 
models all five ensemble members were used. The mean diurnal time series of CAPE was filtered at each grid point by using a harmonic filter that retains the time-mean and wavenumber-1 (24-h) component and these were then area averaged over each box. In the reanalysis, the range of the diurnal variation of CAPE does not exceed $0.5 \mathrm{~kJ} \mathrm{~kg}^{-1}$, except over the GP where it exceeds $1 \mathrm{~kJ} \mathrm{~kg}^{-1}$. Comparing Figs. 4 and 7, there does not appear to be a simple relationship between rainfall and CAPE, although the magnitude of CAPE is generally largest in the convectively active regions of SE, NAM, and the GP. In most locations, the phase of the peak in the diurnal cycle of CAPE is in the afternoon between 1200 and 1600 LST and this is not necessarily in phase with that of rainfall. The maximum in the diurnal variation of CAPE develops several hours before the precipitation maximum in SE, MT, and NAM, while it is out of phase with rainfall in the GP.

The simulated CAPE in the three models is generally in phase with the observed values, with maxima occurring in the afternoon and minima in the nighttime. The GFDL model tends to have earlier maxima compared with the other two models, particularly in MT and NAM where the model has dry biases in summer mean precipitation. Comparing the diurnal variation of CAPE to that of rainfall (cf. Fig. 4) shows no consistent lead-lag relationship in the model. The GFDL model tends to have the CAPE maximum before the rainfall maximum. On the other hand, the NCEP and NASA models tend to have maximum rainfall coincide with the maximum in CAPE in the afternoon. For the GP region only, the NCEP model has the CAPE out of phase with the rainfall, similar to that found in the reanalysis. This implies that, unlike the other locations where the diurnal rainfall variation is largely dictated by the local convective instability, the mechanisms controlling GP rainfall may be fundamentally different (e.g., the MCCs/MCSs and the GPLLJ discussed earlier).

The diurnal variation of CAPE mostly reflects the local planetary boundary layer (PBL) forcing of the deep convection. Figure 8 shows the spatial structure of the diurnal variation of CAPE based on the reanalysis. Two different sets of CAPE values are calculated. The $\mathrm{CAPE}_{\mathrm{sfc}}$ (left panels) indicates that the parcel is lifted from the ground level, and the $\mathrm{CAPE}_{750}$ (right panels) indicates that the parcel is lifted from $750 \mathrm{hPa}$. The latter represents the diurnal variation of CAPE above the boundary layer, which is less affected by the PBL in most areas except for highly elevated terrain. The daily mean value of CAPE is eliminated at each grid point and only the diurnal departures are given. The CAPE $\mathrm{sfc}_{\mathrm{sc}}$ shows a simple structure of daytime maxima (0000 and 1800 UTC) and nighttime minima (0600 and 1200 UTC) over most of the continent. The diurnal variations are strongest in the continental interior, particularly over the eastern side of the Rocky Mountains and adjacent plains.

Compared to the $\mathrm{CAPE}_{\text {sfc }}$, the $\mathrm{CAPE}_{750}$ shows a delayed development in the eastern United States, with negative values at 1800 UTC and positive values at 0000 UTC: this is likely related to the delayed response to the ground heating in the lower troposphere. Strong diurnal variations of $\mathrm{CAPE}_{750}$ are observed over the eastern Rocky Mountains. It is interesting that the positive areas of $\mathrm{CAPE}_{750}$ appear to migrate eastward from the mountains toward the adjacent GP, with positive values extending into the night (0600 and 1200 UTC). The nocturnal positive anomalies of $\mathrm{CAPE}_{750}$ over the GP are unlikely to be related to a delayed response to the PBL forcing, because of its relatively long duration.

Figure 9 provides further insight into the dependence of CAPE on the starting level of the parcel. Here CAPE (Fig. 9) and the convective inhibition (CIN; Fig. 9b) were calculated from all possible starting levels, as the total buoyancy and the negative buoyancy, respectively. Below $850 \mathrm{hPa}$, the diurnal variation of CAPE reflects the development and decay of the PBL associated with surface heat flux. The amplitude of the diurnal variation of CAPE is largest near the ground and decreases with height. The diurnal cycle of CAPE below $850 \mathrm{hPa}$ is mostly in phase with the surface CAPE, but with some delays in time. Above the boundary layer, there is a sharp transition so that the CAPE is out of phase with the surface CAPE. In contrast, the diurnal variation of CIN shows a nighttime maximum and daytime minimum, associated with the nighttime cooling and daytime heating of the boundary layer. However, CIN contributes little to the total CAPE, accounting for less than $10 \%$ of CAPE variation.

The vertical structures of the CAPE simulated by the three models are compared in Fig. 10. The NCEP model shows the smallest diurnal variation of CAPE, whereas the NASA model shows the largest. The models all show an amplitude decrease with height like that in the reanalysis. They also reproduce the vertical tilt in phase, although the slope varies among the models. In the lower troposphere above $850 \mathrm{hPa}$, the GFDL and NASA models produce the observed out-of-phase transition of CAPE, while that is not simulated correctly in the NCEP model.

The out-of-phase relationship between surface and free atmospheric CAPE is also suggested by Zhang (2003), who investigated the diurnal variation of CAPE 
$\mathrm{CAPE}_{\text {sfo }}$
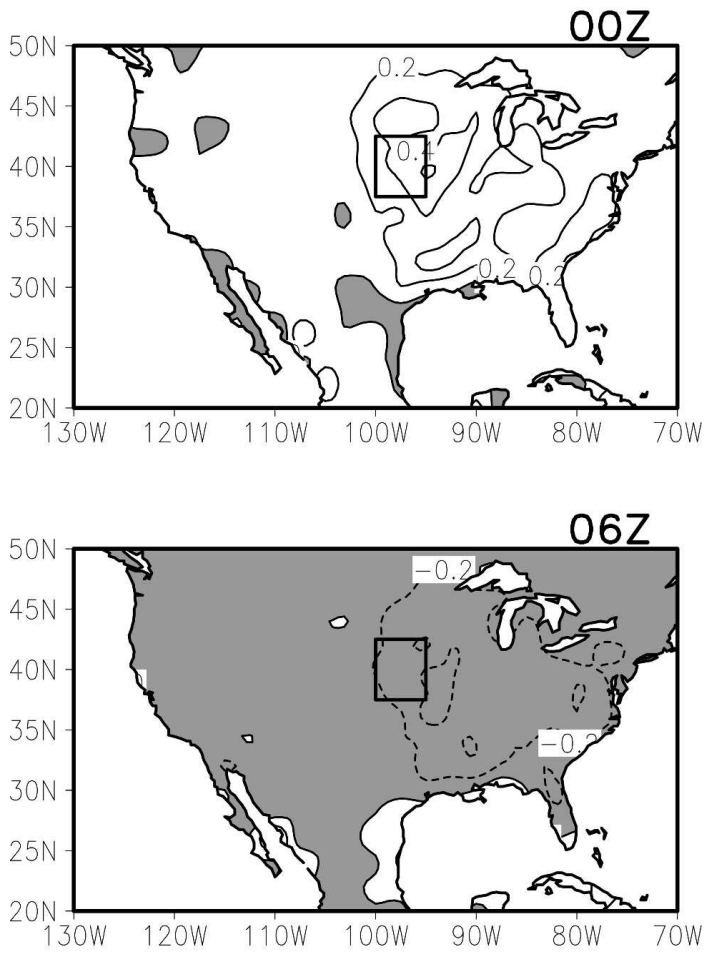

$12 Z$

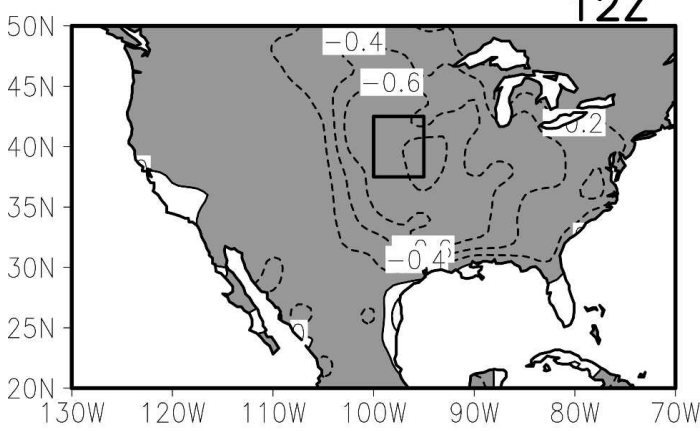

$18 Z$

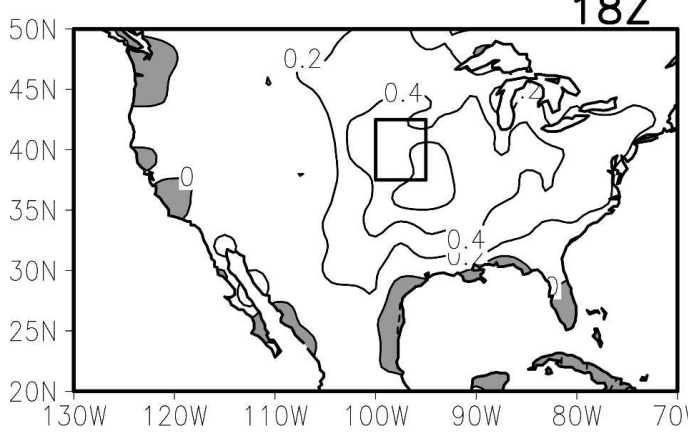

$\mathrm{CAPE}_{750}$
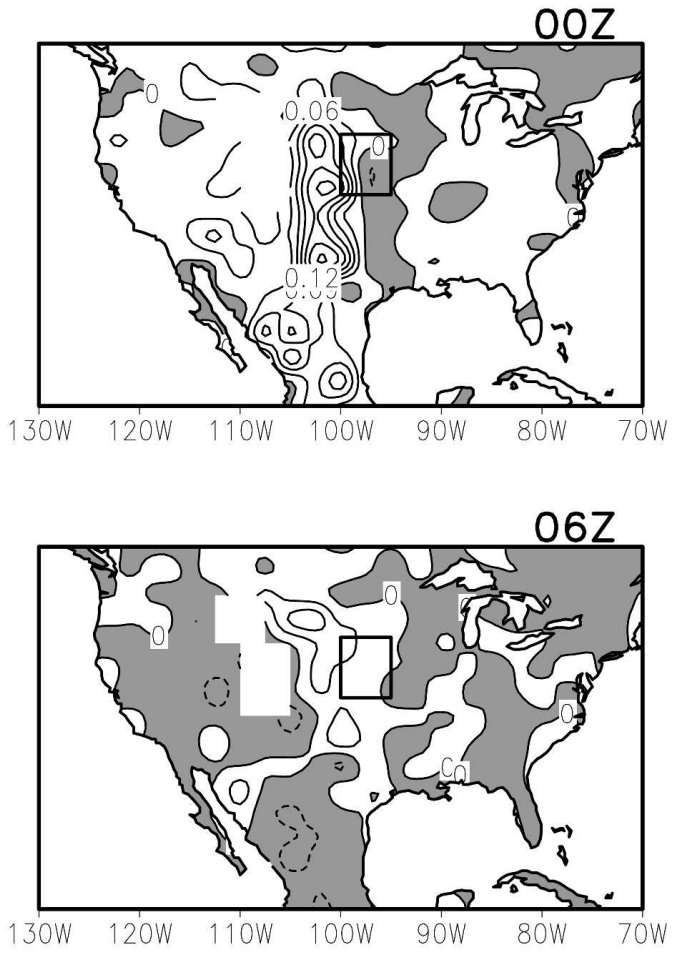

$12 Z$

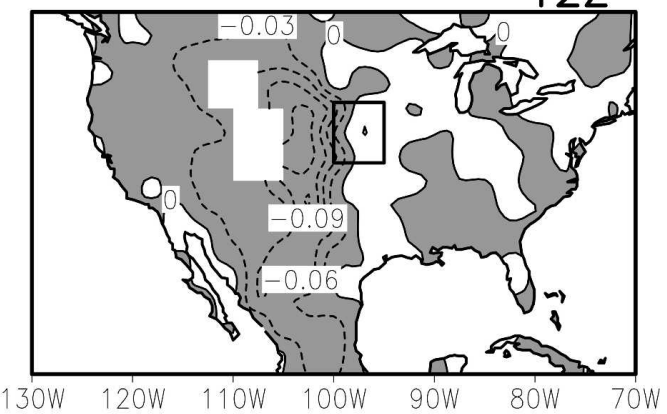

$18 Z$

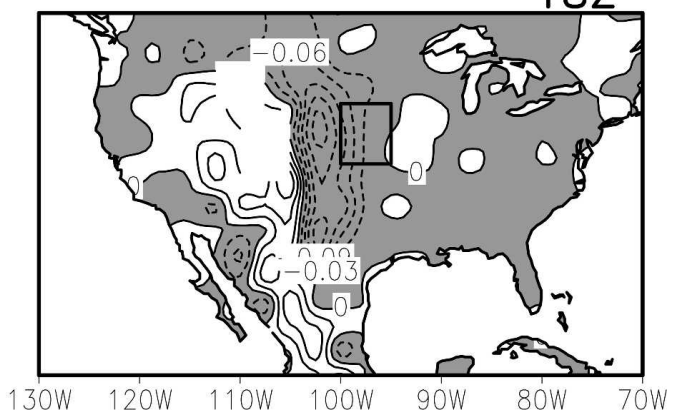

FIG. 8. The diurnal variations of CAPE from NARR (1995 JJA mean). (left) The six-hourly evolution of CAPE that is calculated by lifting parcels from the surface, and (right) same as left panel except that the CAPE calculation is based on parcels that are lifted from $750 \mathrm{hPa}$. The daily mean is subtracted from each grid point and negative values are shaded. The unit is $\mathrm{kJ} \mathrm{kg}^{-1}$. The grid box indicates the Great Plains region $\left(37.5^{\circ}-42.5^{\circ} \mathrm{N}, 100^{\circ}-95^{\circ} \mathrm{W}\right)$ used for averaging CAPE and CIN in Fig. 9. 


\section{(a) CAPE}

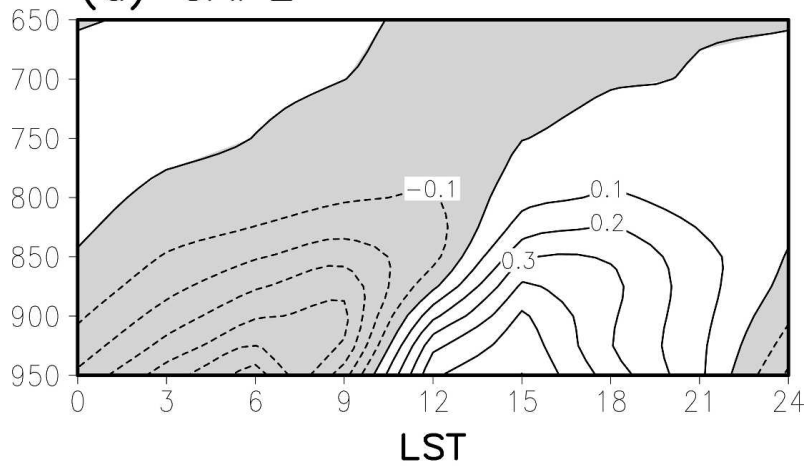

(b) $\mathrm{CIN}$

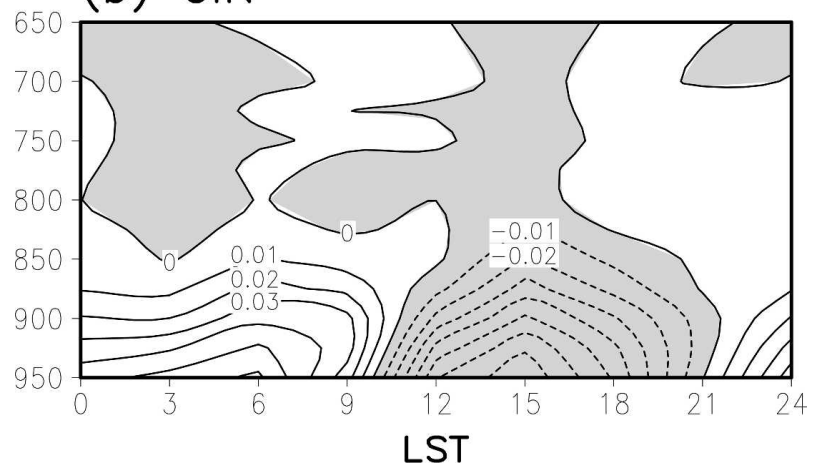

FIG. 9. The vertical and diurnal variations of (a) CAPE and (b) convective inhibition (negative buoyancy) in the Great Plains $\left(37.5^{\circ}-42.5^{\circ} \mathrm{N}, 100^{\circ}-95^{\circ} \mathrm{W}\right)$. The results are from the NARR (JJA 1995) dataset. The daily means are subtracted in both panels. The unit is $\mathrm{kJ} \mathrm{kg}^{-1}$. The vertical axes denote the pressure in $\mathrm{hPa}$.

over the U.S. southern GP using 3-hourly ARM sounding observations. The results of that study showed that the diurnal variation of the tropospheric forcing has a strong in-phase relationship with rainfall, whereas the diurnal variations of surface sensible and latent heat fluxes as well as the thermodynamic properties of the near-surface air are nearly out of phase with the rainfall. The sharp transition in the phase of CAPE and accompanying positive anomalies in the lower troposphere could, for example, be induced by free atmospheric destabilization provided by low-level moisture convergence. This destabilization might be associated with the nocturnal GPLLJ and/or synoptic or mesoscale convective systems migrating eastward from the Rocky Mountains. The role of large-scale controls in the diurnal cycle will be discussed further in the next section.

From a modeling point of view, the result presented in Fig. 10 raises the following question: At what level should deep convection start? Many current convection schemes incorporate ground- or PBL-based convection, which apparently results in the wrong diurnal cycle in rainfall in some regions. For example, the diurnal variation of simulated rainfall in the NASA model is largely tied to the phase of ground CAPE, since the model adopts the lowest two model layers to start convection. This issue will be revisited in section 5, where we examine the sensitivity to parameters in the convection scheme of the NASA model.

\section{b. Low-level jet and moisture flux}

To investigate the role of large-scale dynamical controls on the GP rainfall, the veracity of the LLJ simulation was examined in the three AGCMs. Following Bonner (1968), a "criteria 1" LLJ is defined to occur when the vertical profile of wind speed in a given location has a local maximum of at least $12 \mathrm{~m} \mathrm{~s}^{-1}$ within 1.5 $\mathrm{km}$ from the ground and, above that, it has a local minimum with at least a $6 \mathrm{~m} \mathrm{~s}^{-1}$ wind speed decrease within $3 \mathrm{~km}$ from the ground. The frequency of LLJ occurrence is calculated as a percentage by counting the total number of events and dividing it by total number of days considered for a specific hour of a day. Figure 11 compares the percentage frequency during the daytime (1800 and 0000 UTC average) and the nighttime (0600 and 1200 UTC average). The reanalysis (Fig. 11a) identifies two centers of high frequency (more than $35 \%$ ) - one over the GP (the GPLLJ), and the other over the ocean near the west coast. The GPLLJ shows a strong diurnal variation with the highest frequencies occurring during the nighttime. While these results are for a single summer, the magnitudes and geographical distribution of the GPLLJ are very similar to other estimates based on longer records (e.g., Higgins et al. 1997).

Figures 11b-d shows the LLJ frequencies simulated by the three AGCMs. The models reproduce the two main LLJ locations reasonably well. They also reproduce the strong diurnal variability in the GPLLJ found in the reanalysis with jets occurring much more frequently during the nighttime $(0600+1200$ UTC) than during the daytime, although the magnitude of frequency varies substantially between the models. The GFDL and NASA models overestimate the GPLLJ frequency, whereas the NCEP model underestimates the frequency. It should be noted that these results are sensitive to the definition of the LLJ, especially the choice of the critical value for the maximum wind speed (currently $12 \mathrm{~m} \mathrm{~s}^{-1}$ ). For example, when we recomputed the frequency with slightly smaller critical values (from 12 to $10 \mathrm{~m} \mathrm{~s}^{-1}$ ), the NCEP model LLJ frequency increased substantially, with a maximum frequency of about $30 \%$ in the northern Texas.

It is well known that much of the moisture entering 

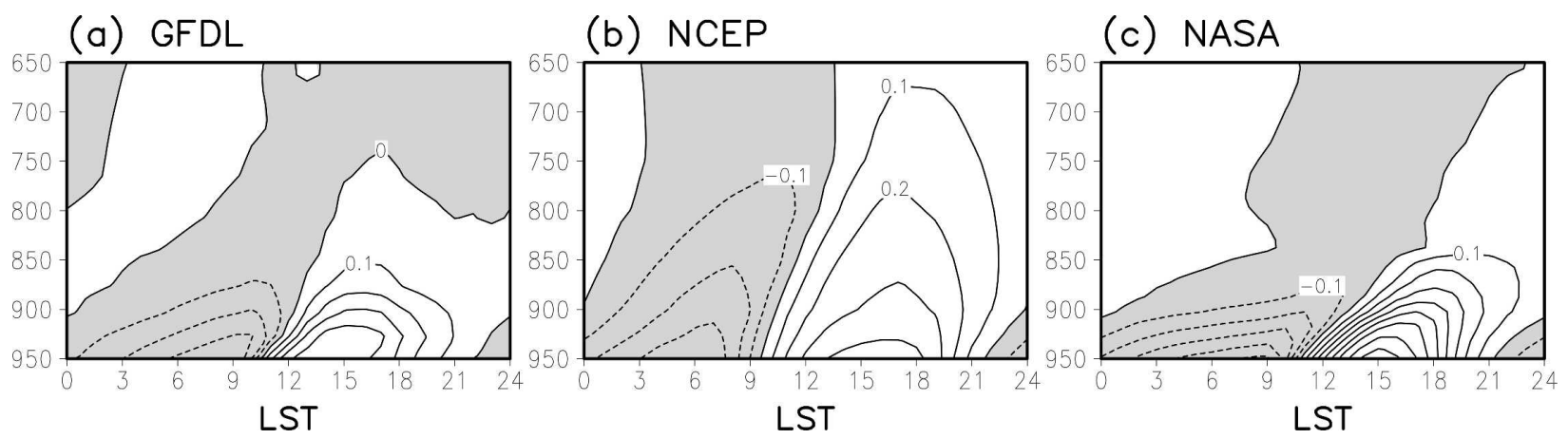

FIG. 10. Same as in Fig. 9a, but for the simulated CAPE from the three AGCMs. The unit is $\mathrm{kJ} \mathrm{kg}^{-1}$.

the GP during the warm season is transported within the lowest few kilometers (Helfand and Schubert 1995; Higgins et al. 1997). To illustrate this we show in Fig. 12 the differences in the $925-\mathrm{hPa}$ moisture flux between the daytime and nighttime. Only the diurnal variation of quadratics of the time-mean wind and moisture are compared here since the contribution from the transients to the total moisture flux is relatively small (Higgins et al. 1997). The reanalysis moisture transport from the Gulf of Mexico to the central United States and the GP shows a nighttime increase, consistent with the nocturnal intensification of the LLJ. The flow is concentrated in a narrow band between $100^{\circ}$ and $90^{\circ} \mathrm{W}$, providing favorable conditions for sustaining convection in the GP. To a large extent, the three AGCMs reproduce these features. In particular, all the models show a realistic nocturnal increase of northward moisture influx into the GP. This suggests that the convection schemes are likely insensitive to the large-scale destabilization induced by the GPLLJ.

\section{c. Eastward-propagating disturbances}

Figure 13 shows the longitude-time cross sections of the diurnal cycle of rainfall along $40^{\circ} \mathrm{N}$ from the observation and the three AGCMs (ensemble averages). The observations show a clear phase lag of the maximum rainfall with longitude. The diurnal cycle of rainfall is such that maximum values occur in the evening at 1800 LST at the top of mountains $\left(105^{\circ} \mathrm{W}\right)$. Moving to the east, the phase of the maximum occurs later such that there is a midnight peak at $100^{\circ} \mathrm{W}$, and a $0500 \mathrm{LST}$ peak around $95^{\circ} \mathrm{W}$. This suggests that the diurnal cycles over the mountains and plains are connected. Furthermore, it is likely that this connection is related to the mesoscale systems that move eastward from the Rocky Mountains onto the plains (Riley et al. 1987; McAnelly and Cotton 1989; Carbone et al. 2002; Nesbitt and Zipser 2003). Since the observed diurnal variability strengthens on the downstream side over the adjacent
GP, it is likely that the nocturnal GPLLJ also plays a role.

The models do poorly in simulating the observed propagation characteristics. The GFDL model has approximately the correct diurnal phase over the top of mountains $\left(105^{\circ} \mathrm{W}\right)$ with an evening maximum (after 1800 LST). However, the model shows relatively fast movement to the east of $100^{\circ} \mathrm{W}$, with variability there that is separated from that of the adjacent plains with a late afternoon or evening maximum (along $100^{\circ}-$ $\left.95^{\circ} \mathrm{W}\right)$. The NCEP model simulates the maximum variability over the top of mountains with an afternoon peak (1500-1600 LST) in rainfall. It shows very slow eastward propagation along the slopes, which is weakly connected with the nighttime rainfall maximum (around 0600 LST) in the adjacent plains. The NASA model shows an in-phase variation in precipitation between the mountains and plains, with an afternoon maximum. In the mountains, there is a secondary peak in the rainfall at midnight, which is simulated by the GFDL model too.

We further investigated the composites of only those cases with nocturnal rainfall over the GP, but the results are not qualitatively different from those in Fig. 13. In general, the models have difficulty in correctly simulating the observed evening maximum over the mountains (earlier peak), and the location of maximum variability is simulated too far west. The eastward propagation is much weaker than the observed and any nocturnal GP rainfall in the three models shows little connection with the mountain-initiated convective activity. The models also fail to capture the downslope propagation of the dry zone (precipitating less than 0.5 mm day ${ }^{-1}$ ) during the nighttime: this likely reflects a poor representation of the local mountain-valley circulation. Of course the relatively coarse horizontal resolution (about $2^{\circ}$ ) of the simulations is one likely reason for the unrealistic behavior. The results may, however, also indicate a fundamental weakness in the parameter- 
(a) NARR

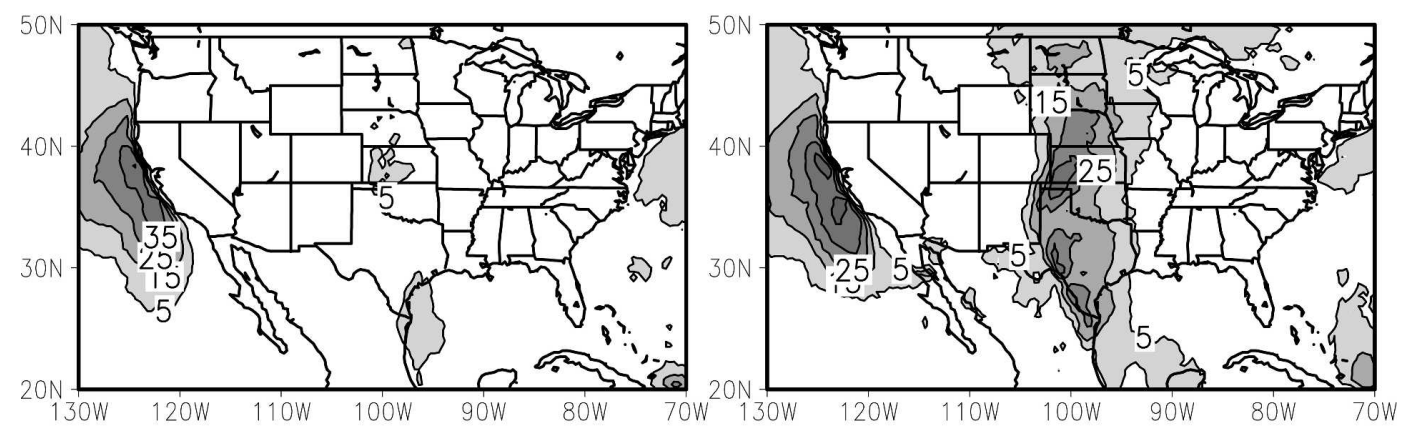

(b) GFDL

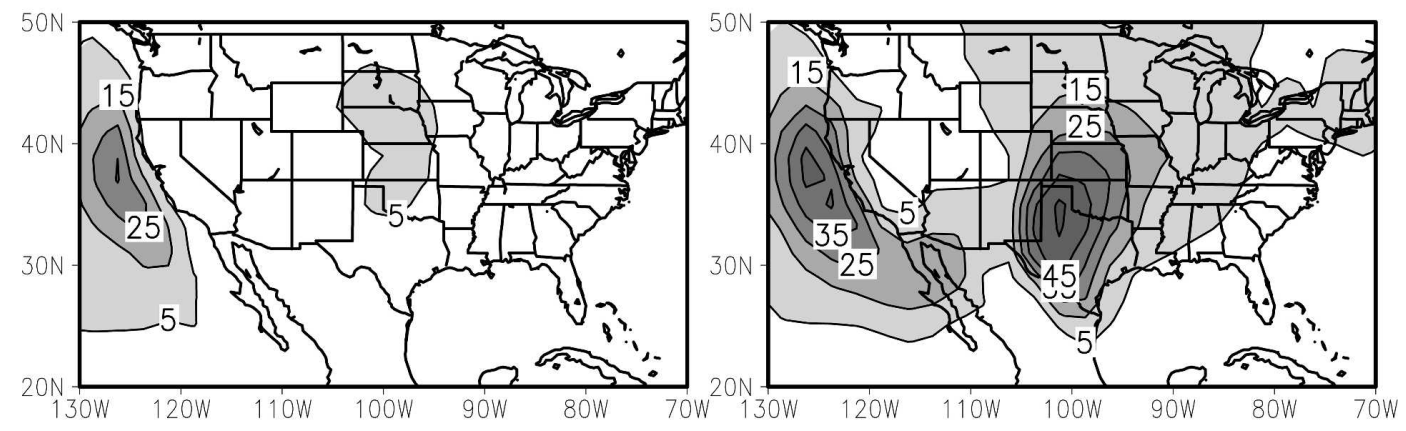

(c) NCEP

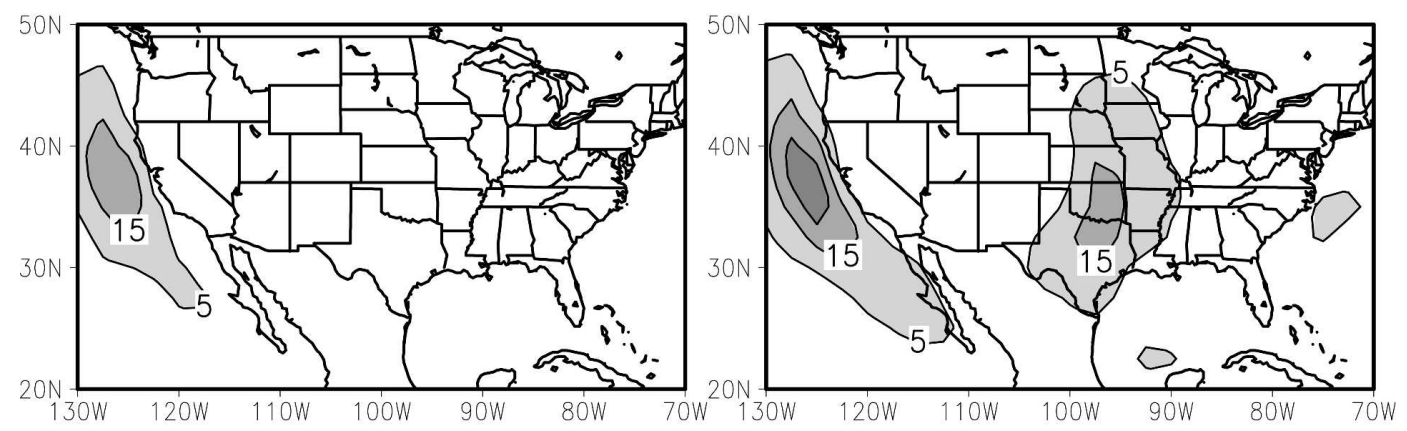

(d) NASA

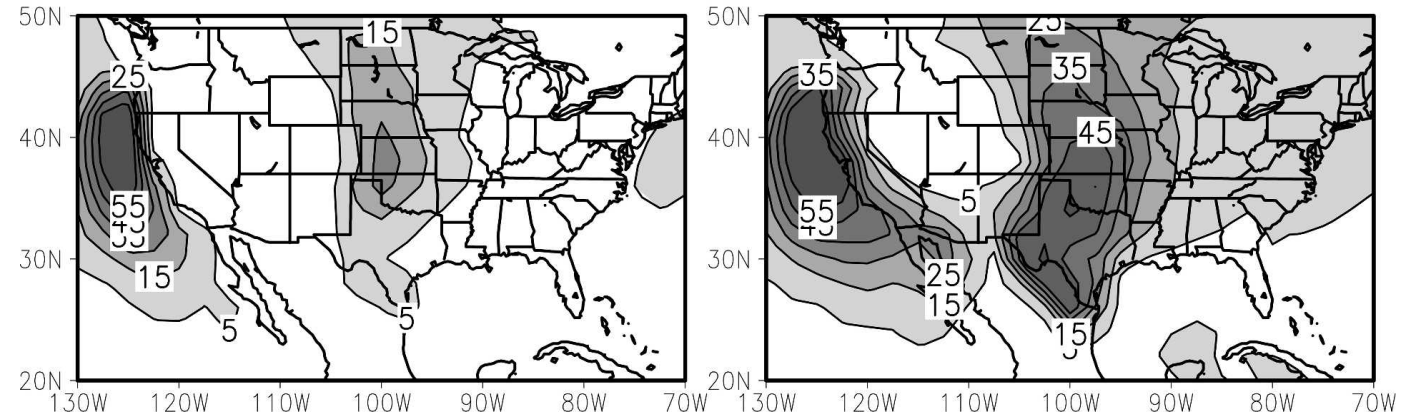

FIG. 11. (left) Daytime (1800 and 0000 UTC average) and (right) nighttime (0600 and 1200 UTC average) low-level jet frequencies computed from (a) NARR, and from simulations with the (b) GFDL model, (c) NCEP model, and (d) NASA model. The low-level jet occurrence is based on criterion 1 of Bonner (1968). 
(a) NARR

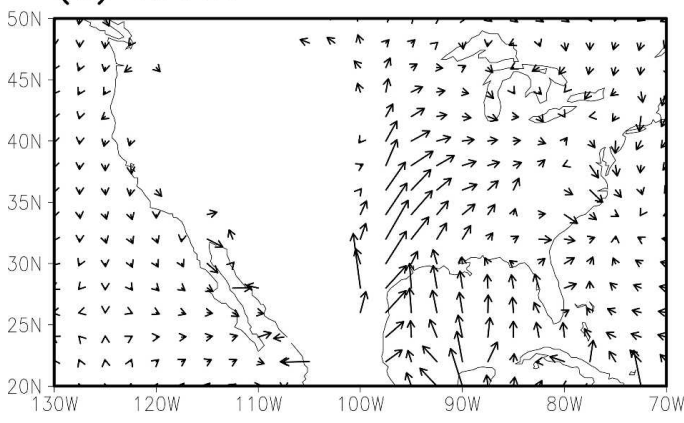

(c) NCEP

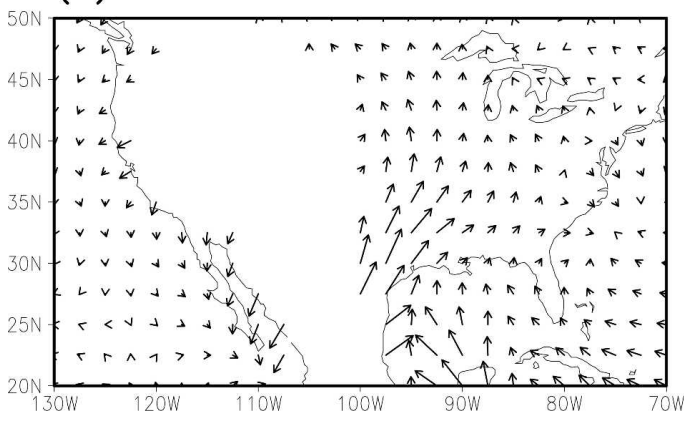

(b) GFDL

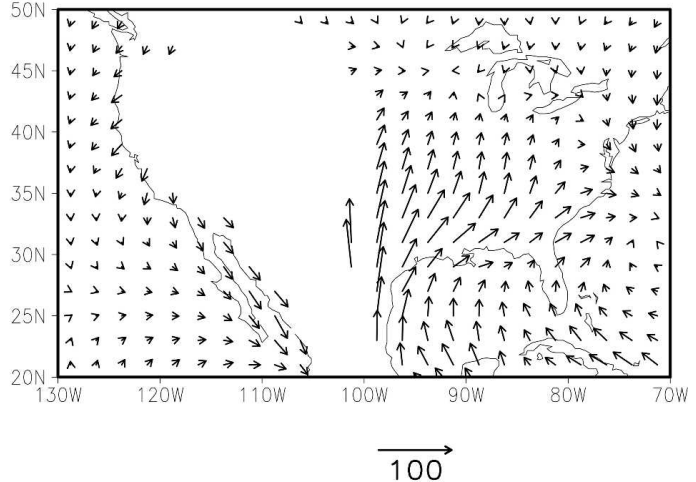

(d) NASA

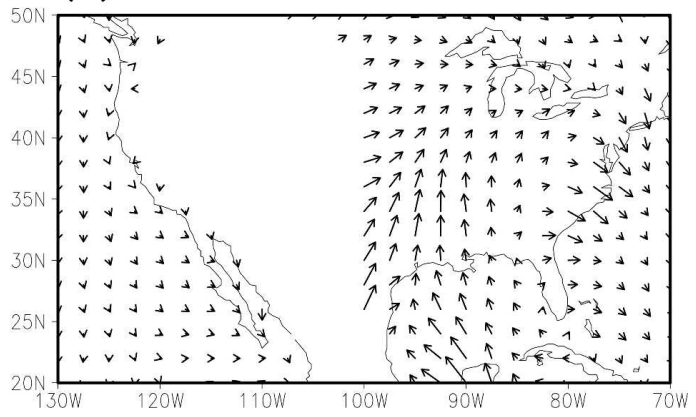

FIG. 12. The nighttime $(0600+1200$ UTC) minus daytime $(1200+1800$ UTC) moisture flux differences at the 925-hPa level from the NARR and the three models. The unit is $\left(\mathrm{m} \mathrm{s}^{-1}\right)\left(\mathrm{g} \mathrm{kg}^{-1}\right)$.

izations of deep convection that cannot explicitly resolve the mesoscale organized convective systems.

\section{Sensitivity to the convection scheme}

It is clear from the previous sections that the three AGCMs show substantial differences in the representation of diurnal convection, especially over the GP. Two of the AGCMs (GFDL and NASA) produce very little nocturnal rainfall in the GP, whereas the NCEP model produces fairly realistic nocturnal rainfall. On the other hand, all three AGCMs produced realistic variations of the GPLLJ and associated moisture fluxes. In addition, the models produced realistic diurnal variations of CAPE. The prevalence of afternoon convection over the GP in the GFDL and NASA models implies that the convection schemes are too sensitive to the local variation of CAPE. One possible reason for this sensitivity is that current deep convection schemes are based on buoyancy closure (approximately CAPE) and do not explicitly deal with dynamical controls. The latter is only included implicitly by the models, by taking into account the temperature and humidity variations caused by large-scale advection. The inphase relationship between CAPE and rainfall in the models suggests that the models are too sensitive to the boundary layer forcing near the ground, and/or that the large-scale controls on convection such as the dynamical forcing (convergence) by the LLJ are too weak.

Of course, any relationship between CAPE and convection can be altered by including additional trigger or inhibition functions in the parameterization. We suspect, for example, that the NCEP model successfully simulates the GP nocturnal rainfall because it has a dynamically dependent CWF formulation. As mentioned in section $2 b$, the NCEP model has a critical CWF that depends on the cloud-base vertical motion in the model, and this allows strong convection as the large-scale rising motion becomes strong. In fact, we find that over the GP the cloud base upward vertical motion in the NCEP model leads by a few hours the simulated nocturnal precipitation maximum, suggesting that the convergence associated with the LLJ may act as a dynamical trigger for the nocturnal rainfall.

Another notable deficiency in the model simulations is the earlier phase of the precipitation maximum over most land regions (this appears to be a common problem in AGCMs). For example, in the southeast United States, the NCEP and NASA models show a general tendency to rain in the early afternoon, whereas the 
(a) HPD

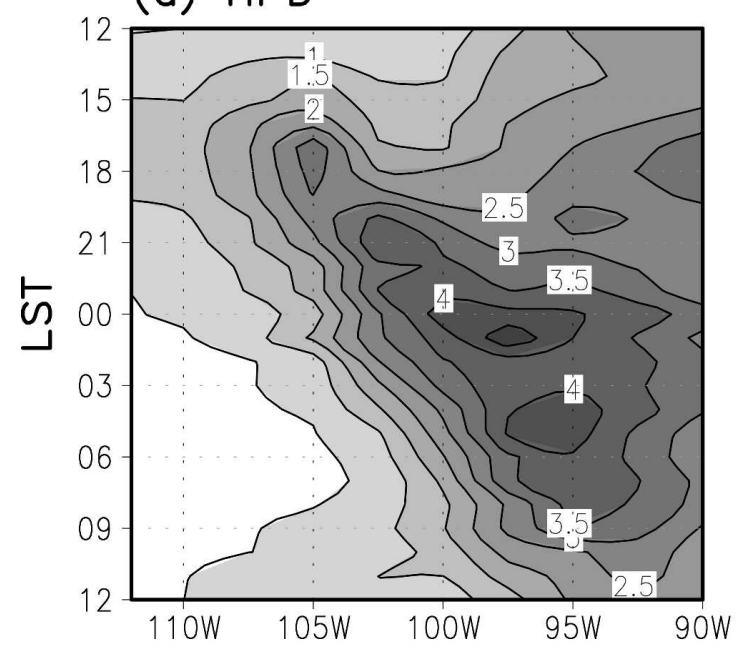

(c) NCEP

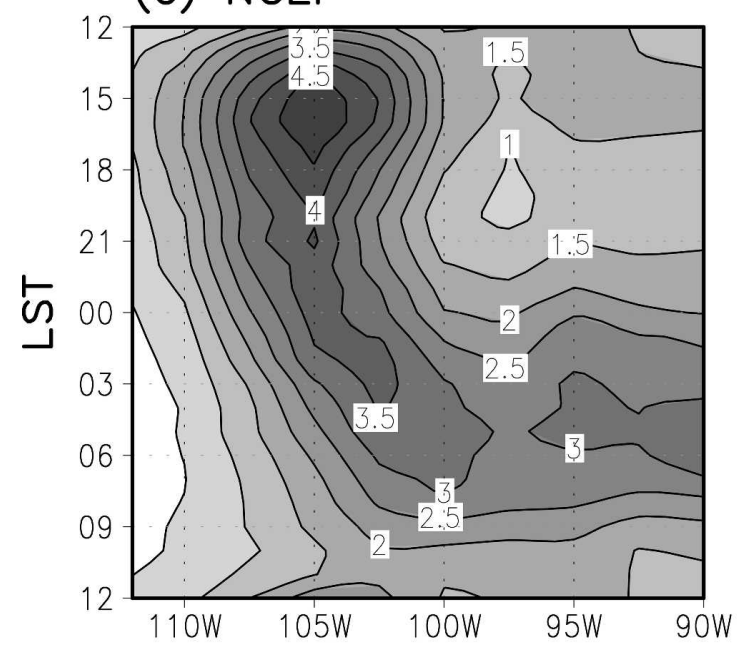

(b) GFDL

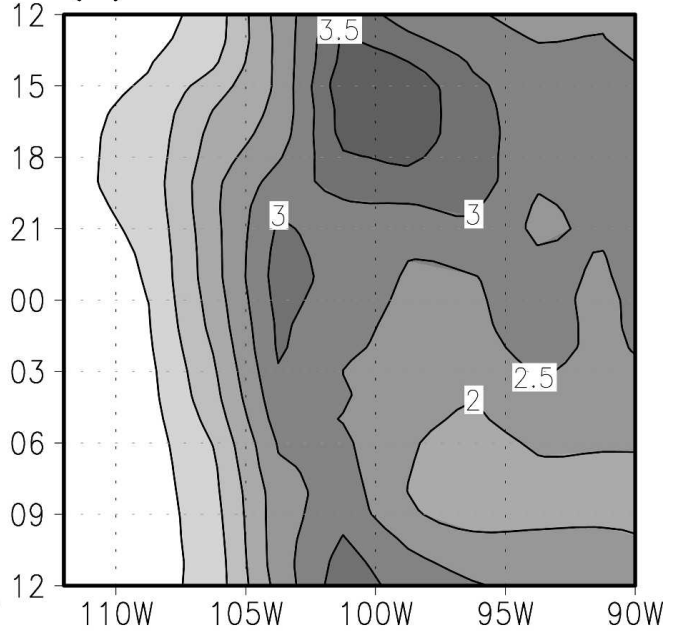

(d) NASA

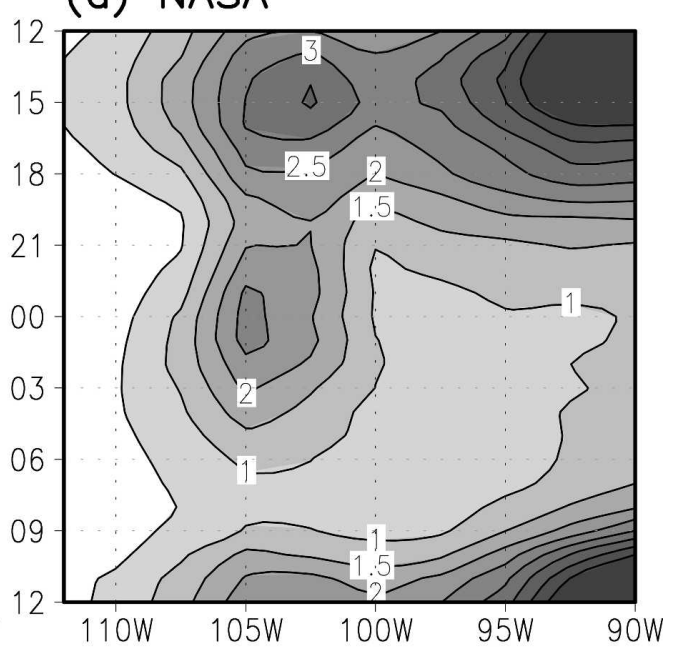

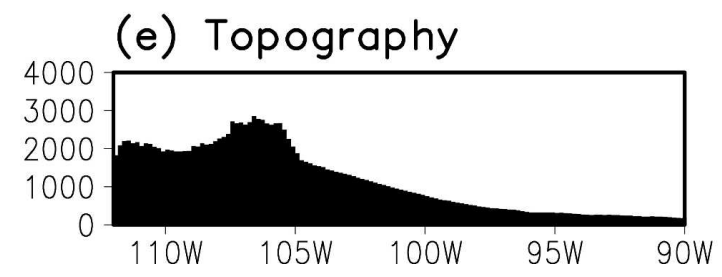

FIG. 13. Longitude-time plots of the diurnal cycle of rainfall $\left(\mathrm{mm} \mathrm{day}^{-1}\right)$ at $40^{\circ} \mathrm{N}$ latitude (the average between $37.5^{\circ}$ and $42.5^{\circ} \mathrm{N}$ ). From (a) the HPD (1983-2002), (b) the GFDL model, (c) the NCEP model, and (d) the NASA model. (e) The longitudinal variation of surface elevation.

GFDL model simulates an evening rainfall maximum at about the right time. Since the GFDL and NASA models both use the RAS convection scheme, we should be able to isolate those differences in the implementations of the scheme that led to the differences in the diurnal cycle. A careful comparison of the two model codes showed two major differences between the schemes. One is the definition of the starting level or subcloud layer for convection. The GFDL model uses the LCL to define the subcloud layer properties, whereas the NASA model averages the temperature and humidity for the lowest two model levels. The other difference is the convection relaxation time scale: the GFDL model uses a much longer time scale (see section $2 \mathrm{~b}$ ). To test the sensitivities to those parameters, we have carried out additional experiments with the NASA model (see 
TABLE 2. Description of the sensitivity experiments with the NASA model.

\begin{tabular}{lcc}
\hline \hline & Convection starting level & Relaxation time scale \\
\hline Control & $2(\sigma=0.98)$ & $0.5 \mathrm{~h}$ \\
EXP1 & $10(\sigma=0.86)$ & $0.5 \mathrm{~h}$ \\
EXP2 & $2(\sigma=0.98)$ & $2-12 \mathrm{~h}$ \\
EXP3 & $10(\sigma=0.86)$ & $2-12 \mathrm{~h}$ \\
\hline
\end{tabular}

the Table 2). In EXP1, we increased the number of averaging levels to be the lowest 10 levels $(\sigma=0.85)$. This effectively makes the convection start at a higher level. As suggested by Fig. 10, this can delay the phase of convection as it uses the diurnal variation of the PBL mean, rather than values near the ground. In EXP2, we modified the relaxation time scale in the NASA model to be the same as that of the GFDL model. Ideally, the increase in the relaxation time scale should extend the response time of adjustment toward the equilibrium state, and subsequently increase the lifetime of convection. In EXP3, we tested the combined impact of changing the convection starting levels and the relaxation time.

Figure 14 shows the amplitudes and phases of the diurnal cycle of rainfall from the control and the three sensitivity experiments. Each experiment consisted of a single summer (June-August) initialized on 1 May. The control experiment (Fig. 14a) shows early afternoon convection, consistent with Fig. 3d. EXP1 (Fig. 14b) shows that an effectively higher starting level tends to systematically delay the phase of the diurnal cycle by a few hours in most locations, with little change in the amplitude. EXP2 (Fig. 14c) shows that the longer relaxation time scales produce some changes in phase though not uniformly so, and an overall decrease in the amplitude of the diurnal cycle. The phase is delayed by several hours in the southeastern United States and southern Mexico, whereas a mixed signal of daytime and nighttime rainfall is obtained over the Rocky Mountains and GP regions. When the two modifications are combined (EXP3; shown in Fig. 14d), there is a substantial improvement in the simulation of the diurnal cycle. The phase shows more delay than in either EXP1 or EXP2 in most locations. The evening rainfall is much closer in phase to that of the observed over the Rocky Mountains and the southeastern United States. Moreover, the geographical distribution of the amplitude looks much more realistic. The above results suggest that fundamental improvements in the simulation of the diurnal cycle will require parameterizations that are able to better capture the coupling between convection and boundary layer processes.

\section{Summary and concluding remarks}

This study analyzed the observed and simulated diurnal cycle of warm-season precipitation over the continental United States and northern Mexico. The geographical distribution of the observed diurnal cycle of rainfall is characterized by three distinct regions: the Rocky Mountains, the GP, and the southeastern United States. The Rocky Mountains and the southeastern United States show a late afternoon or evening maximum; while the GP shows a maximum around midnight. Although the convection schemes in the three AGCMs have the same buoyancy closure based on Arakawa and Schubert (1974), the diurnal cycle of rainfall is quite different among the models. All the models produce a daytime rainfall maximum over the Rocky Mountains and the southeastern United States, but the maximum tends to occur a few hours too early. One of the most prominent deficiencies is in the simulation of the diurnal cycle of precipitation over the GP. Two of the AGCMs produce an afternoon maximum of rainfall-opposite to the observed nocturnal maximum over this region.

An analysis of the space-time structure of the diurnal cycle shows substantial differences between the southeastern United States and the Rocky Mountains. The diurnal cycle of precipitation over the southeastern United States is characterized by a standing oscillation that amplifies in the late afternoon and evening and is suppressed during the night, apparently a reflection of the local convective instability. Mountain-initiated convection over the Rocky Mountains, however, tends to propagate away, leading to an eastward movement of convective activity toward the adjacent plains in the local evening and nighttime. The nocturnal precipitation over the GP is also closely associated with anomalous southerly low-level winds, implying that large-scale dynamics and moisture transport associated with the nocturnal LLJ may be important in maintaining convection over that region (Rasmusson 1967; Helfand and Schubert 1995; Higgins et al. 1997). All three AGCMs have a reasonable diurnal variation in the LLJ, yet the relationship between nocturnal rainfall and the LLJ is poorly represented.

The role of local convective instability was analyzed by diagnosing CAPE. The simulated CAPE in all three models is generally in phase with the CAPE in the reanalysis, with afternoon maxima and nighttime minima, roughly in phase with the diurnal cycle of rainfall in most locations. On the other hand, over the GP, the observed precipitation and CAPE are out of phasea feature not well captured by the models. As suggested by Zhang (2003), the reason for this may be that 
(a) CNTR
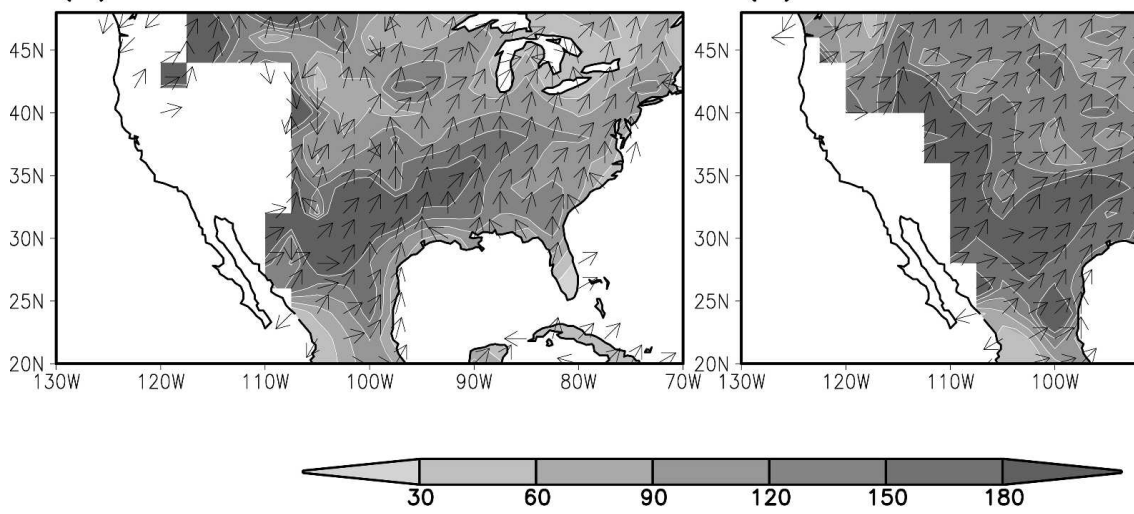

(c) EXP2

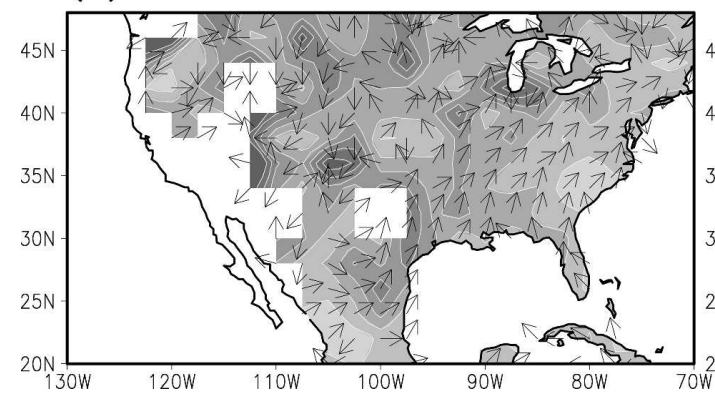

(d) EXP3

(b) EXP1
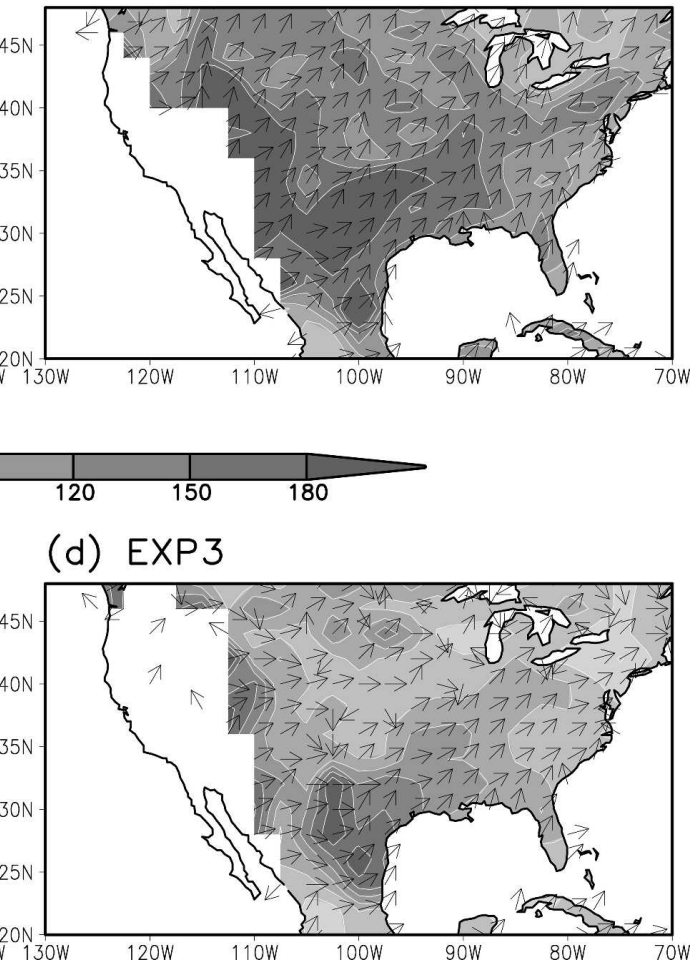

FIG. 14. Same as in Fig. 3, but for the sensitivity experiments involving the RAS convection scheme in the NASA model: (a) the control run, (b) EXP1 (tests the starting level of the convection), (c) EXP2 (relaxation time-scale test), and (d) EXP3 (includes both the change in convection starting level and relaxation time scale). See the text for details.

the convection schemes are too strongly coupled to the boundary layer forcing, and too weakly coupled to the large-scale dynamical forcing (destabilization). This interpretation of the basic problem in the GP is supported by our analysis of CAPE, which shows an out-of-phase relationship between surface and free atmospheric CAPE. In fact, the buoyancy closure scheme implemented in the three AGCMs responds too strongly to the daytime heating and nighttime cooling of the PBL. This explains the prevalence of daytime convection in two of the AGCMs (GFDL and NASA), even though these models simulate reasonable nocturnal LLJs and associated moisture fluxes. The successful simulation of nocturnal rainfall in the GP in the NCEP model is ascribed to the implementation of a dynamical trigger in the convection scheme that is a function of the large-scale vertical motion at the cloud base.

In addition to the problems specific to the GP, the models tend to rain several hours too early over most land regions. This is a well-known problem that occurs in many other models (Yang and Slingo 2001; Collier and Bowman 2004; Dai and Trenberth 2004). Dai et al. (1999) suggested that the criteria for the onset of moist convection may be too weak so that moist convection starts too early and occurs too often. In the current study, we took advantage of the fact that the GFDL and NASA models share basically the same convection scheme (RAS) in order to understand the role of different trigger/inhibition functions and different tunable parameters. In particular, we carried out several sensitivity experiments to isolate the reasons for why the NASA model shows an early peak in afternoon rainfall, while the GFDL model shows a later development of convection that agrees well with the observations. Two major differences were identified: one is the definition of the convection starting level or subcloud layer, and the other is the relaxation time scale. When the convection scheme in the NASA model was modified to be like that in the GFDL in terms of convection starting level and relaxation time, the simulation of diurnal cycle was substantially improved. The modified run with the NASA model successfully delays the phase of convection by several hours to get the evening convection in most regions closer to that found in the GFDL model and the observations. The geographical distribution of the amplitude was also improved. 
The results from the sensitivity experiment to the modified convection scheme suggest that the interaction between PBL and deep convection needs to be improved in the model parameterizations. This includes, but is not confined to, improvements in the origination level of deep convection and enabling middle-level convection in the free atmosphere. Also, the large-scale dynamical controls on deep convection need to be better parameterized, particularly for regions such as the Great Plains where the low-level jets and mesoscale convective systems seem to play important roles in the warm-season precipitation process ( $\mathrm{Ri}$ ley et al. 1987; Carbone et al. 2002). The eastward propagation of the convective activity is poorly represented in the current coarse-resolution climate model simulations. The impact of higher resolution on this and other features of the North American monsoon are currently under study (partly addressed in Lee et al. 2007). More fundamentally, traditional parameterizations of convection are ill posed to represent the MCCs/MCSs that are frequently observed over this region, as they cannot adequately treat the organization and advection of mesoscale systems. This aspect of the problem can be more rigorously examined with models that include cloud-resolving parameterizations.

Acknowledgments. This study benefited from numerous conference calls involving a number of scientists with a wide range of relevant experience. Special thanks go to Julio Bacmiester, Wayne Higgins, Kingtse Mo, Baijun Tian, Guang Zhang, Hualu Pan, Philip Pegion, Man-Li Wu, Mark Helfand, Craig Collier, Xianan Jiang, Kyu-Myong Kim, Tom Bell, and Yogesh Sud for their valuable comments during the conference calls. We also thank Wei Shi who kindly provided the NCEP/ CPC Hourly Precipitation Dataset, and Fedor Mesinger and Wesley Ebisuzaki for the North American Regional Reanalysis products. Comments from three anonymous reviewers led to considerable improvements in the presentation. This study was supported by NOAA's Office of Global Programs GEWEX Americas Prediction Project/Pan American Climate Studies (PACS/GAPP) North American Warm Season Precipitation Initiative.

\section{REFERENCES}

Anderson, B. T., J. O. Roads, S. C. Chen, and H. M. H. Juang, 2001: Model dynamics of summertime low-level jets over northwestern Mexico. J. Geophys. Res., 106, 3401-3413.

Anderson, J. L., and Coauthors, 2004: The new GFDL global atmosphere and land model AM2-LM2: Evaluation with prescribed SST simulations. J. Climate, 17, 4641-4673.
Arakawa, A., and W. H. Schubert, 1974: Interaction of a cumulus cloud ensemble with the large-scale environment, Part I. J. Atmos. Sci., 31, 674-701.

Arritt, R. W., and M. J. Mitchell, 1994: Variability of the Great Plains low-level jet and its influence on mesoscale convection. Proc. Sixth Conf. on Mesoscale Processes, Portland, OR, Amer. Meteor. Soc., 151-153.

Bacmeister, J. T., P. J. Pegion, S. D. Schubert, and M. J. Suarez, 2000: Atlas of seasonal means simulated by the NSIPP 1 atmospheric GCM. NASA Tech. Memo. 104606, Vol. 17, 194 pp.

Berbery, E. H., 2001: Mesoscale moisture analysis of the North American monsoon. J. Climate, 14, 121-137.

Bergman, J. W., 1997: A numerical investigation of cloud diurnal variations. J. Climate, 10, 2330-2350.

Betts, A., and J. H. Ball, 1995: The FIFE surface diurnal cycle climate. J. Geophys. Res., 100, 25 679-25 693.

, — , A. C. M. Beljaars, M. J. Miller, and P. A. Viterbo, 1996: The land surface-atmosphere interaction: A review based on observational and global modeling perspectives. $J$. Geophys. Res., 101, 7209-7225.

Bonner, W. D., 1968: Climatology of the low-level jet. Mon. Wea. Rev., 96, 833-850.

Carbone, R. E., J. D. Tuttle, D. A. Ahijevych, and S. B. Trier, 2002: Inferences of predictability associated with warm season precipitation episodes. J. Atmos. Sci., 59, 2033-2056.

Chang, D. H., L. Jiang, and S. Islam, 2000: Issues of soil moisture coupling in MM5: Simulation of the diurnal cycle over the FIFE area. J. Hydrometeor., 1, 477-490.

Chen, M., R. E. Dickinson, X. Zeng, and A. N. Hahmann, 1996: Comparison of precipitation observed over the continental United States to that simulated by a climate model. J. Climate, 9, 2233-2249.

Collier, J. C., and K. P. Bowman, 2004: Diurnal cycle of tropical precipitation in a general circulation model. J. Geophys. Res., 109, D17105, doi:10.1029/2004JD004818.

Dai, A. G., and C. Deser, 1999: Diurnal and semidiurnal variations in global surface wind and divergence fields. J. Geophys. Res., 104 (D24), 31 109-31 125.

— and K. E. Trenberth, 2004: The diurnal cycle and its depiction in the Community Climate System Model. J. Climate, 17, 930-951.

_ _, F. Giorgi, and K. E. Trenberth, 1999: Observed and modelsimulated diurnal cycles of precipitation over the contiguous United States. J. Geophys. Res., 104, 6377-6402.

Douglas, M. W., and S. H. Li, 1996: Diurnal variation of the lower-tropospheric flow over the Arizona low desert from SWAMP-1993 observations. Mon. Wea. Rev., 124, 1211-1224.

Easterling, D. R., and P. J. Robinson, 1985: The diurnal variation in thunderstorm activity in the United States. J. Climate Appl. Meteor., 24, 1048-1058.

Garratt, J. R., P. B. Krummel, and E. A. Kowalczyk, 1993: The surface energy balance at local and regional scales-A comparison of general circulation model results with observations. J. Climate, 6, 1090-1109.

Giorgi, F., and C. Shields, 1999: Tests of precipitation parameterizations available in the latest version of the NCAR regional climate model (RegCM) over the continental U.S. J. Geophys. Res., 104, 6353-6376.

Grell, G. A., 1993: Prognostic evaluation of assumptions used by cumulus parameterizations. Mon. Wea. Rev., 121, 764-787.

Groisman, P. Y., R. S. Bradley, and B. Sun, 2000: The relationship of cloud cover to near-surface temperature and humidity: 
Comparison of GCM simulations with empirical data. J. Climate, 13, 1858-1878.

Helfand, H. M., and S. D. Schubert, 1995: Climatology of the simulated Great Plains low-level jet and its contribution to the continental moisture budget of the United States. J. Climate, 8, 784-806.

Higgins, R. W., J. E. Janowiak, and Y. Yao, 1996: A Gridded Hourly Precipitation Data Base for the United States (19631993). NCEP/Climate Prediction Center Atlas 1, NCEP/ NWS/NOAA, 47 pp.

— , Y. Yao, E. S. Yarosh, J. E. Janowiak, and K. C. Mo, 1997: Influence of the Great Plains low-level jet on the summertime precipitation and moisture transport over the central United States. J. Climate, 10, 481-507.

Higgins, W., and Coauthors, 2006: The NAME 2004 field campaign and modeling strategy. Bull. Amer. Meteor. Soc., 87, 79-94.

Hong, S.-Y., and H.-L. Pan, 1996: Nonlocal boundary layer vertical diffusion in a medium-range forecast model. Mon. Wea. Rev., 124, 2322-2339.

$\mathrm{Hu}, \mathrm{Q} ., 2003$ : A multidecadal variation in summer season diurnal rainfall in the central United States. J. Climate, 16, 174-178.

Koster, R. D., and M. J. Suarez, 1996: Energy and water balance calculations in the Mosaic LSM. NASA Tech. Memo. 104606, Vol. 9, 60 pp.

—_ and Coauthors, 2004: Regions of strong coupling between soil moisture and precipitation. Science, 305, 1138-1140.

Lee, M.-I., and Coauthors, 2007: Sensitivity to horizontal resolution in the AGCM simulations of warm season diurnal cycle of precipitation over the United States and northern Mexico. J. Climate, 20, 1862-1881.

Leung, L. R., L. O. Mearns, F. Giorgi, and R. Wilby, 2003: Workshop on regional climate research: Needs and opportunities. Bull. Amer. Meteor. Soc., 84, 89-95.

Lim, G. H., and A. S. Suh, 2000: Diurnal and semidiurnal variations in the time series of 3-hourly assimilated precipitation by NASA GEOS-1. J. Climate, 13, 2923-2940.

Lin, X., D. A. Randall, and L. D. Fowler, 2000: Diurnal variability of the hydrological cycle and radiative fluxes: Comparisons between observations and a GCM. J. Climate, 13, 4159-4179.

Lock, A. P., A. R. Brown, M. R. Bush, G. M. Martin, and R. N. B. Smith, 2000: A new boundary layer mixing scheme. Part I: Scheme description and single-column model tests. Mon. Wea. Rev., 128, 3187-3199.

Louis, J., M. Tiedtke, and J. Geleyn, 1982: A short history of the PBL parameterization at ECMWF. Proc. ECMWF Workshop on Planetary Boundary Layer Parameterization, Reading, United Kingdom, European Centre for Medium-Range Weather Forecasts, 59-80.

Maddox, R. A., 1980: Mesoscale convective complexes. Bull. Amer. Meteor. Soc., 61, 1374-1387.

Markowski, P. M., and D. J. Stensrud, 1998: Mean monthly diurnal cycles observed with PRE-STORM surface data. J. Climate, 11, 2995-3009.

McAnelly, R. L., and W. R. Cotton, 1989: The precipitation life cycle of mesoscale convective complexes over the central United States. Mon. Wea. Rev., 117, 784-808.

Mesinger, F., and Coauthors, 2006: North American regional reanalysis. Bull. Amer. Meteor. Soc., 87, 343-360.

Moorthi, S., and M. J. Suarez, 1992: Relaxed Arakawa-Schubert: A parameterization of moist convection for general circulation models. Mon. Wea. Rev., 120, 978-1002.

Nesbitt, S. W., and E. J. Zipser, 2003: The diurnal cycle of rainfall and convective intensity according to three years of TRMM measurements. J. Climate, 16, 1456-1475.

Pan, H.-L., and L. Mahrt, 1987: Interaction between soil hydrology and boundary layer developments. Bound.-Layer Meteor., 38, 185-202.

_ , and W.-S. Wu, 1995: Implementing a mass flux convection parameterization package for the NMC medium-range forecast model. NMC Office Note 409, 40 pp.

Randall, D. A., J. A. Abeles, and T. G. Corseti, 1985: Seasonal simulations of the planetary boundary layer and boundary layer stratocumulus clouds with a general circulation model. J. Atmos. Sci., 42, 641-676.

_ - Harshvardhan, and D. A. Dazlich, 1991: Diurnal variability of the hydrological cycle in a general circulation model. $J$. Atmos. Sci., 48, 40-62.

Rasmusson, E. M., 1967: Atmospheric water vapor transport and the water balance of North America: Part I. Characteristics of the water vapor flux field. Mon. Wea. Rev., 95, 403-426.

Reynolds, R. W., N. A. Rayner, T. M. Smith, D. C. Stokes, and W. Wang, 2002: An improved in situ and satellite SST analysis for climate. J. Climate, 15, 1609-1625.

Riley, G. T., M. G. Landin, and L. F. Bosart, 1987: The diurnal variability of precipitation across the Central Rockies and adjacent Great Plains. Mon. Wea. Rev., 115, 1161-1172.

Rotstayn, L., 1997: A physically based scheme for the treatment of stratiform clouds and precipitation in large-scale models. I: Description and evaluation of the microphysical processes. Quart. J. Roy. Meteor. Soc., 123, 1227-1282.

Schubert, S. D., H. M. Helfand, C.-Y. Wu, and W. Min, 1998: Subseasonal variations in warm-season moisture transport and precipitation over the central and eastern United States. J. Climate, 11, 2530-2555.

Schulz, J. P., L. Dumenil, and J. Polcher, 2001: On the land surface-atmosphere coupling and its impact in a single-column atmospheric model. J. Appl. Meteor., 40, 642-663.

Slingo, A., R. C. Wilderspin, and S. J. Brentnall, 1987: Simulation of the diurnal cycle of outgoing longwave radiation with an atmospheric GCM. Mon. Wea. Rev., 115, 1451-1457.

Soden, B. J., 2000: The diurnal cycle of convection, clouds, and water vapor in the tropical upper troposphere. Geophys. Res. Lett., 27, 2173-2176.

Sundqvist, H., E. Berge, and J. E. Kristjansson, 1989: Condensation and cloud parameterization studies with a mesoscale numerical weather prediction model. Mon. Wea. Rev., 117, 1641-1657.

Tian, B., B. J. Soden, and X. Wu, 2004: Diurnal cycle of convection, clouds, and water vapor in the tropical upper troposphere: Satellites versus a general circulation model. J. Geophys. Res., 109, D10101, doi:10.1029/2003JD004117.

— I. M. Held, N.-C. Lau, and B. J. Soden, 2005: Diurnal cycle of summertime deep convection over North America: A satellite perspective. J. Geophys. Res., 110, D08108, doi:10.1029/ 2004JD005275.

Tiedtke, M., 1983: The sensitivity of the time-mean large-scale flow to cumulus convection in the ECMWF model. Proc. ECMWF Workshop on Convection in Large-Scale Models, Reading, United Kingdom, European Centre for MediumRange Weather Forecasts, 297-316.

_ 1993: Representation of clouds in large-scale models. Mon. Wea. Rev., 121, 3040-3061.

Tokioka, T., K. Yamazaki, A. Kitoh, and T. Ose, 1988: The equatorial 30-60 day oscillation and the Arakawa-Schubert pen- 
etrative cumulus parameterization. J. Meteor. Soc. Japan, 66, 883-901.

Trenberth, K. E., A. Dai, R. M. Rasmussen, and D. B. Parsons, 2003: The changing character of precipitation. Bull. Amer. Meteor. Soc., 84, 1205-1217.

Wallace, J. M., 1975: Diurnal variations in precipitation and thunderstorm frequency over the conterminous United States. Mon. Wea. Rev., 103, 406-419.

Wilson, C. A., and J. F. B. Mitchell, 1986: Diurnal variations and cloud in a general circulation model. Quart. J. Roy. Meteor. Soc., 112, 347-369.
Xu, K. M., and D. A. Randall, 1996: A semiempirical cloudiness parameterization for use in climate models. J. Atmos. Sci., 53, 3084-3102.

Yang, G. Y., and J. Slingo, 2001: The diurnal cycle in the Tropics. Mon. Wea. Rev., 129, 784-801.

Zhang, G. J., 2003: Roles of tropospheric and boundary layer forcing in the diurnal cycle of convection in the U.S. southern Great Plains. Geophys. Res. Lett., 30, 2281, doi:10.1029/ 2003GL018554.

Zhao, Q. Y., and F. H. Carr, 1997: A prognostic cloud scheme for operational NWP models. Mon. Wea. Rev., 125, 1931-1953. 